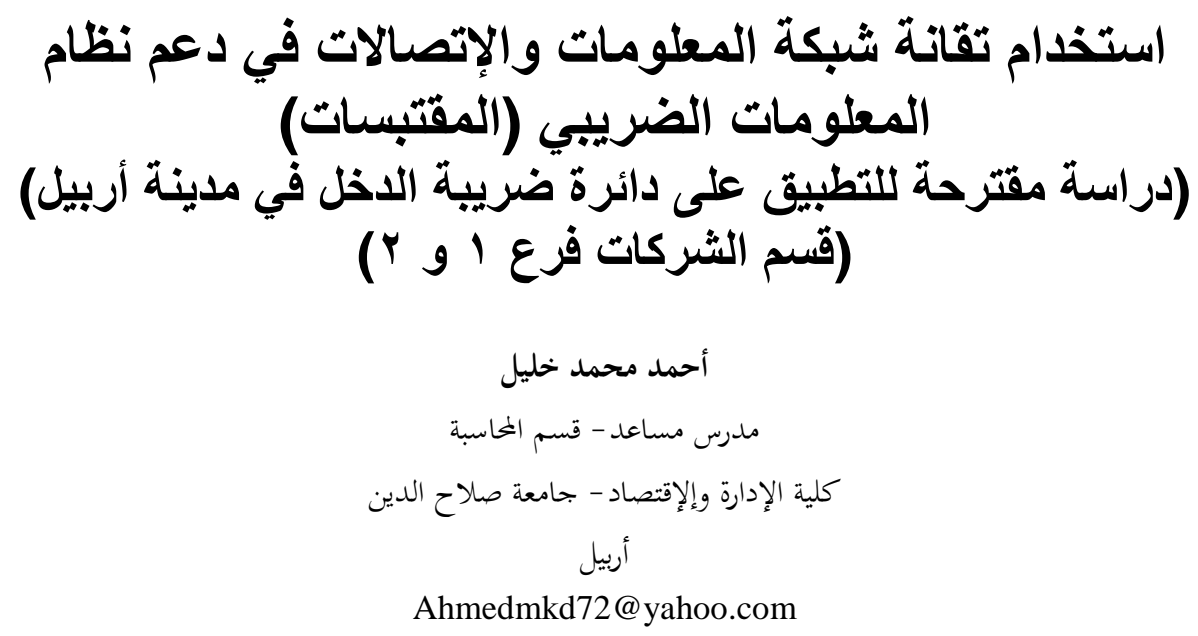

بعد ظهور شبكة المعلومات والإتصالات والآفاق الجديدة التي هيأتها هذه التقاتئة للانفتاح

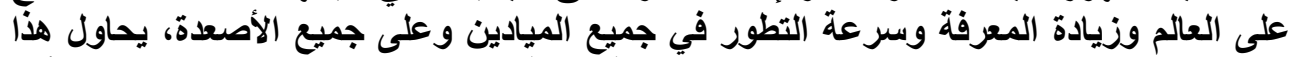

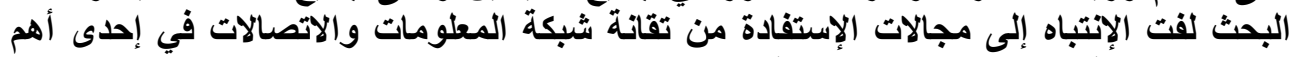

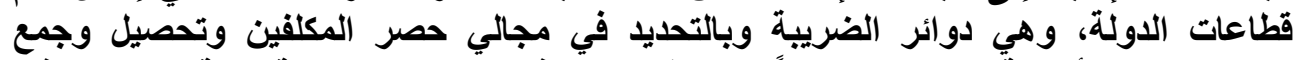

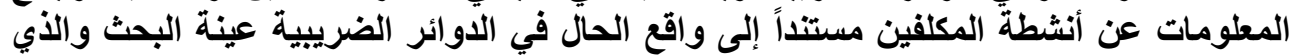

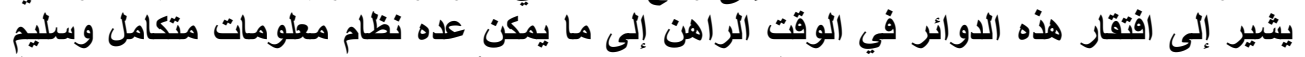

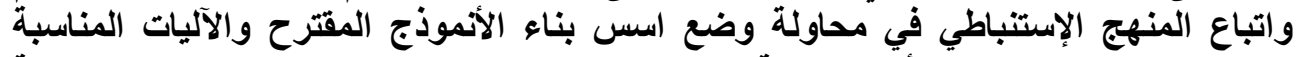

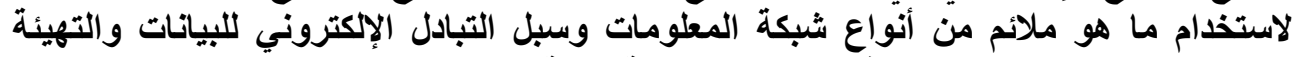

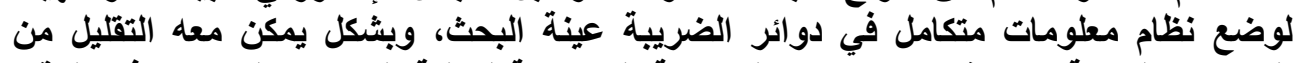

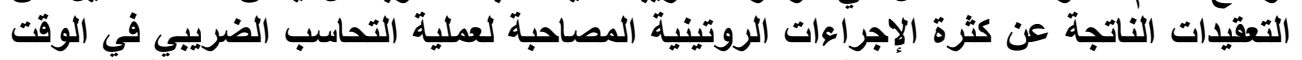

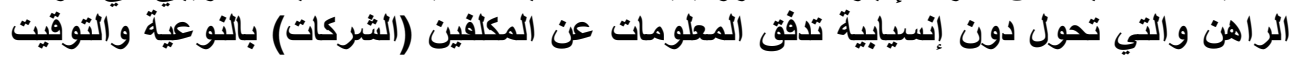

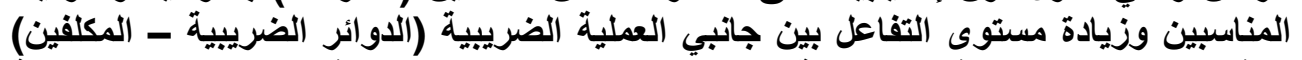

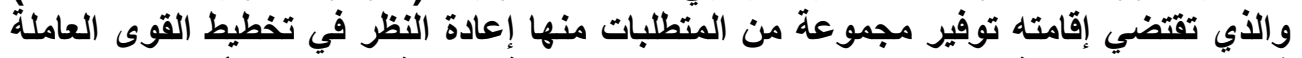

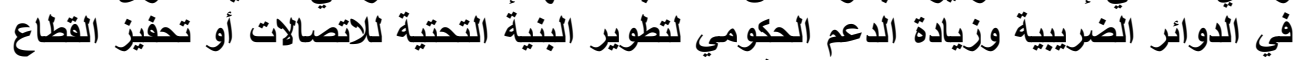

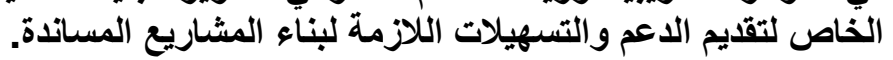

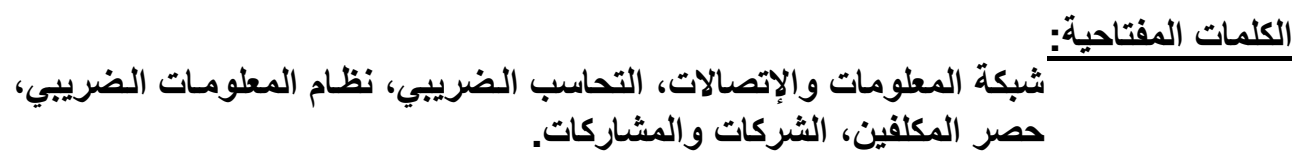




\title{
Using Information Network and Communication Technology in Supporting Tax Information System (Quotations): A Proposed Study for Application on Tax Directory of Erbil, Companies Department 1, 2)
}

\author{
Ahmed M. Khalil \\ Assistant Lecturer \\ Department of Accounting \\ University of Salah-Aldden / Erbil \\ Ahmedmkd72@yahoo.com
}

\begin{abstract}
The emergence of information and communication networks and new perspectives opened by this technology to the world, increase the knowledge and the speed of development in all field. This research attempts to draw the attention to the areas to take advantage of the IT networks and communications in one of the most important sectors of the state, taxation departments, specifically in the areas of inventory charge and collect information on the activities of mandate. The process of collecting information (quotes) on the activities of mandate is however the first step. The task in the process of settling accounts tax may affect the process of settling accounts tax on the principles and rules of sound science. Thus, this may raise the level of service to both sides of the process (tax departments - in charge). The weakness in this process caused a lot of problems at the present time due to the lack of a focal process on the basis of stable and sound. The methods of reliance in valuation and assessment are usually based on inaccurate information and inappropriate character. This consequently causes turn to the lack of justice in taxation and the sense of non charge payment of tax evasion and an attempt to pay, which affect the final outcome on the economy of the State.
\end{abstract}

\section{Keywords :}

Information and communication network, taxation, tax information system, areas of inventory charge, companies and partnership.

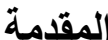

تبذل الدوائر الضريبية جهوداً كبيرة لتنمية قدر اتها في مجال توفير البيانـات اللازمـة التي تساعدها في عملية تحصبل الضر ائب (بمختلف أنواعها)، وتعد عملية حصر المكلفين

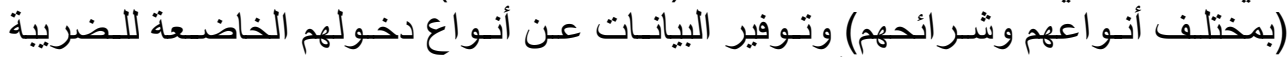

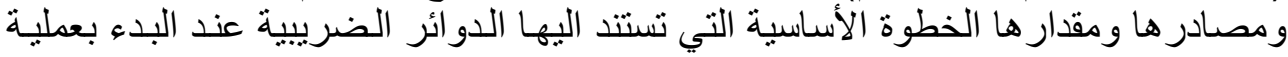
التحاسـب الضريبي مـع هؤلاء المكلفين لينم بعد ذلك تقدير الضر ائب وربطها وتحصيلها بحسب مواد القانون الضريبي النافذئ. إن ما وفرته تقانة شبكة المعلومات و الاتصالات من خدمات كثيرة في مجالات تو فير

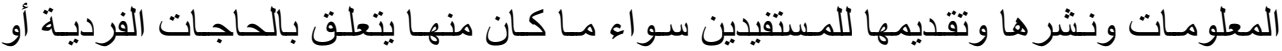

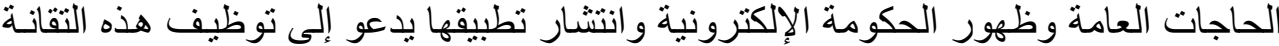
للإستفادة من ثمار ها في تحقيق أهداف جودة الخدمة المقدمـة وتوفير القو اعد العلميـة و الفنبـة

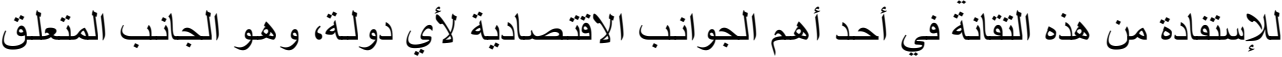




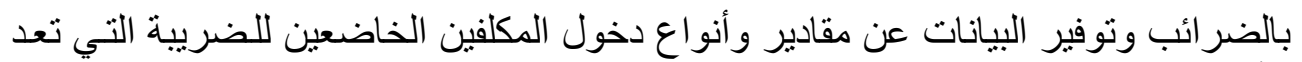

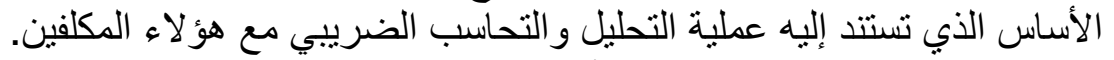

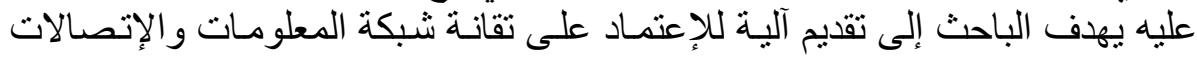

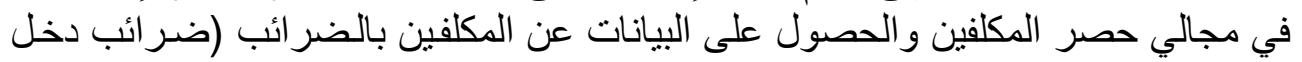

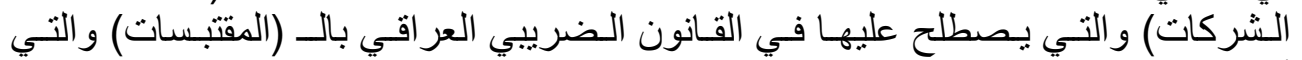

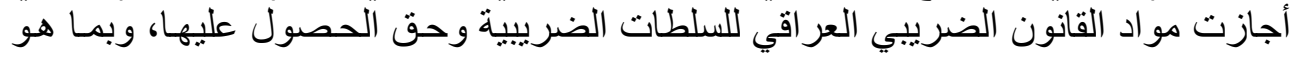

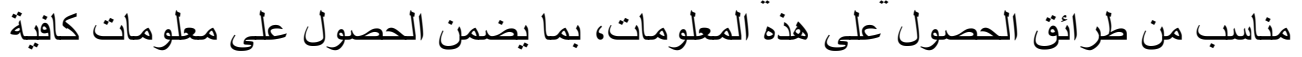

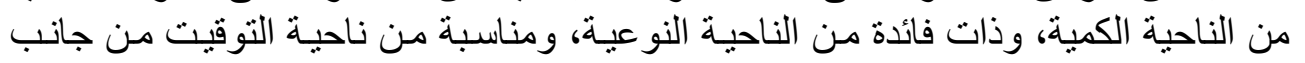

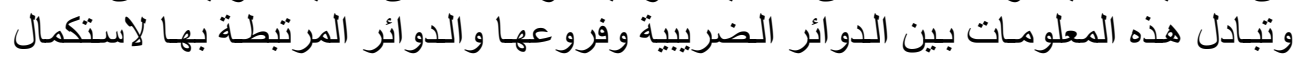

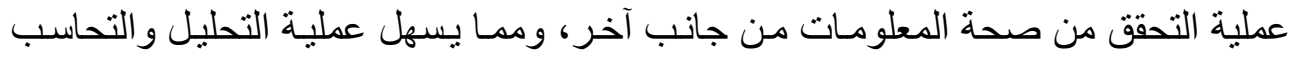

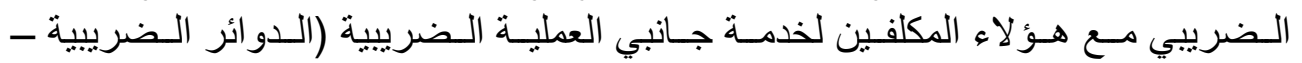
(المكلفين).

\section{مشكلة البحث}

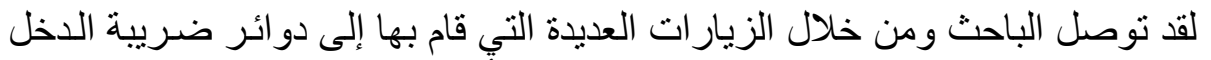

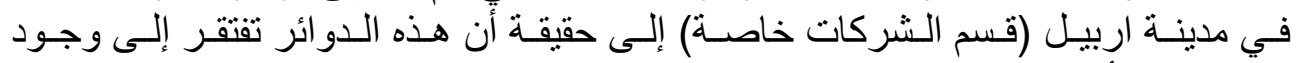

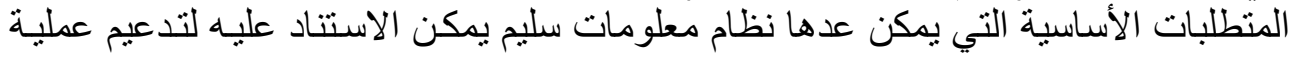

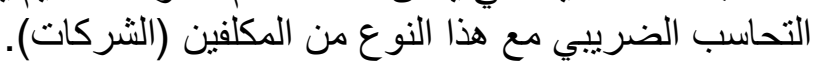

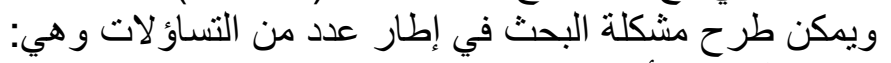

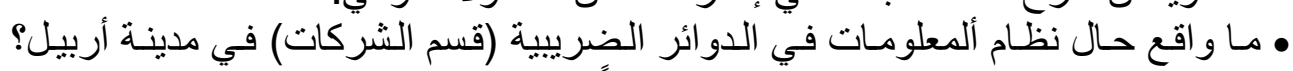

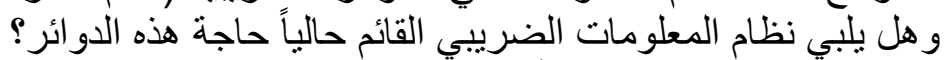

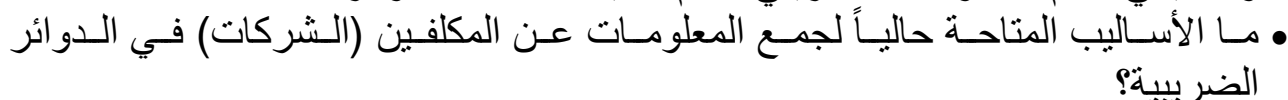

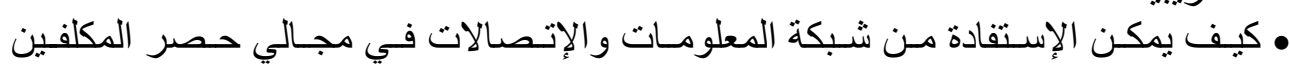

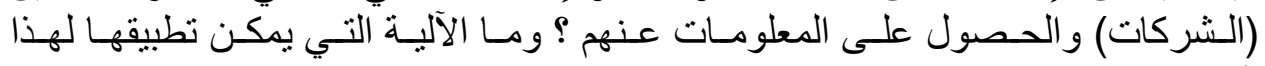
الغرض؟ • مـا المستلزمات الو اجب توفير هـا لإعداد القاعدة التي على أساسـها يمكن استخدام شبكة

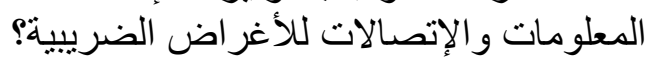

أهمية البحثة أهمية هذا البحث من كونه يمثل خطوة من خطو ات عديدة على طريق وضع نظسام

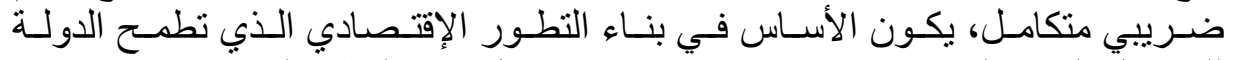

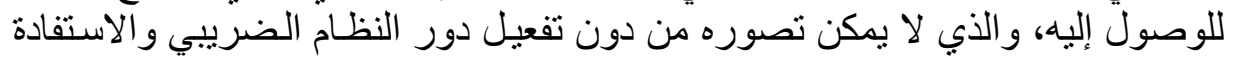

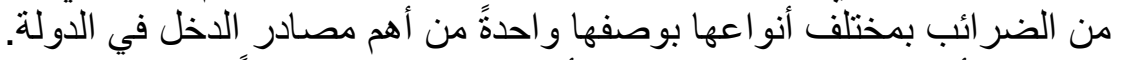

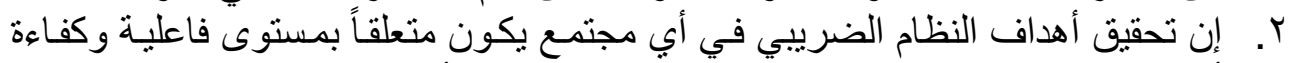

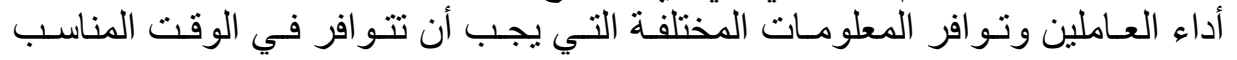


r. أهمية استخدام تقانة شبكة المعلومـات و الإتصالات في مجال العمل الضريبي لمـا لها

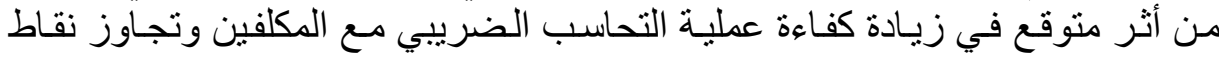

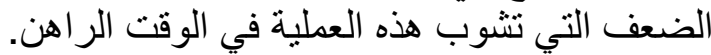

$$
\text { يهذف البحث إلى البح الآتي: }
$$

أهداف البحث

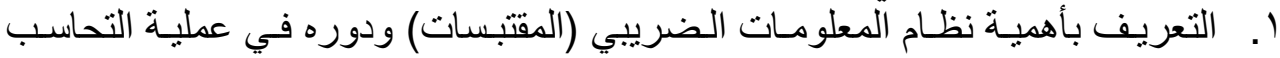

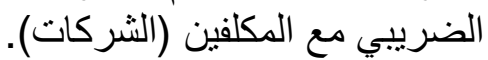

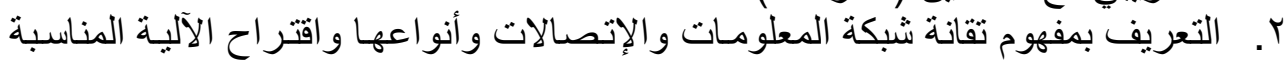

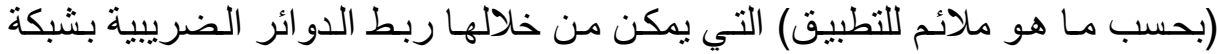

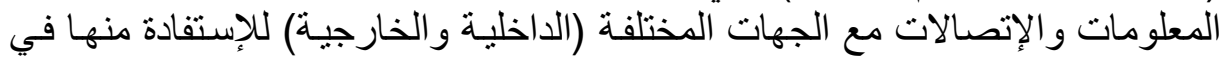

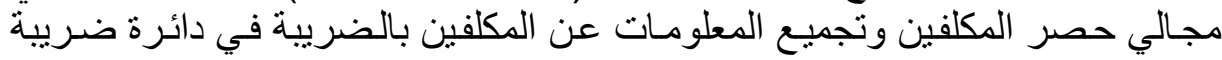

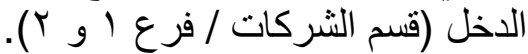
r. توضيح المز ايا الناتجة عن استخدام تقانة شبكة المعلومات والاتصالات من قبل الدوائر الضريبية (عينة البحث).

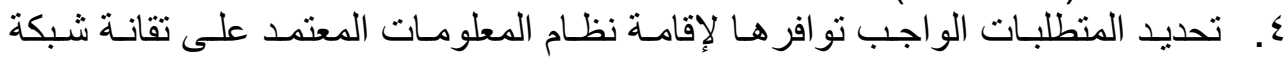
المعلومات و الإتصالات في الدوائر الضريبية (عينة البحث).

$$
\text { فرضية البحث ميتم خلال مفردات هذا البحث التحقق من الفرضيات الآتية: }
$$

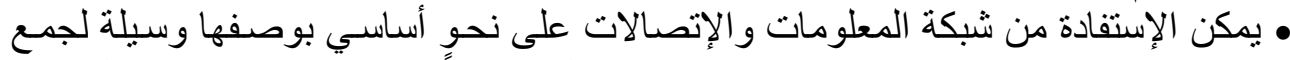

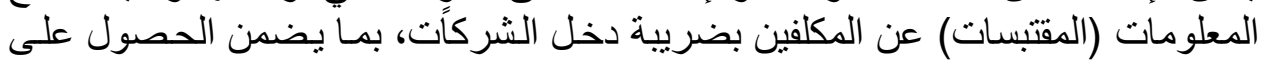

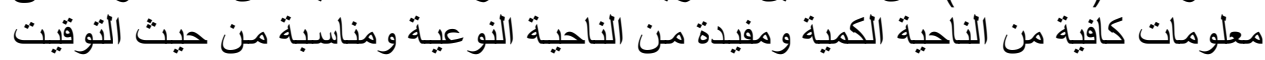

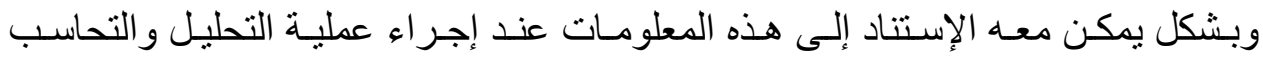

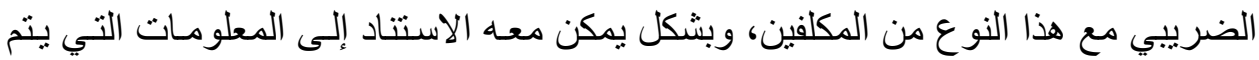

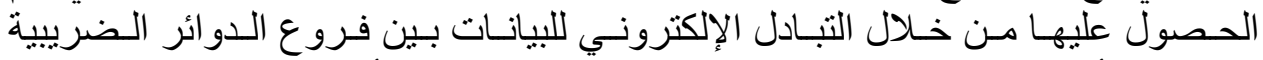

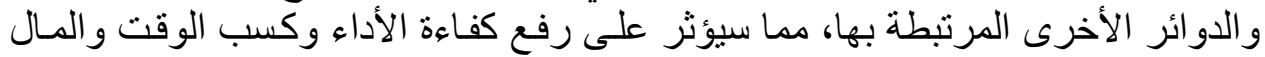

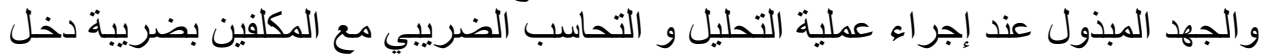
الشركات.

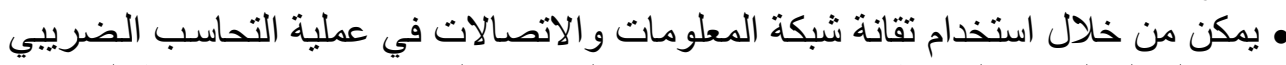

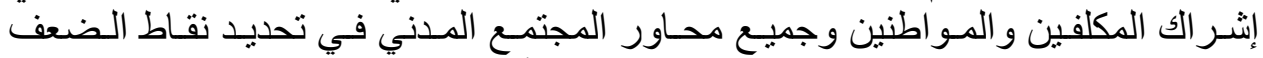

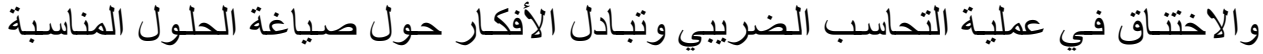
لمشاكل المكلفين و احتياجاتهم.

تم إعداد البحث بـالتطبيق على مديريـة ضـريبة الدخل في في مدينـة أربيل، وتم اختيـار عينة وحدود البحث قسم الثركات بفرعيه ا و ب بوصفها عبنة أولية للتطبيق. 
منهجية البحث لإتمام هذا البحث تم الإعتماد على الأساليب المنهجية الآتية:

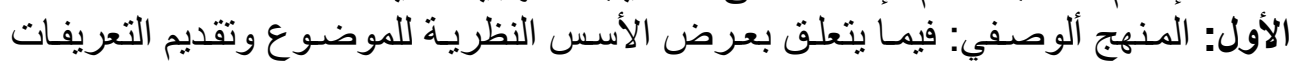

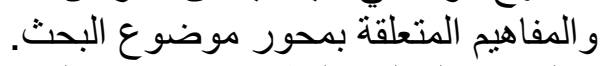

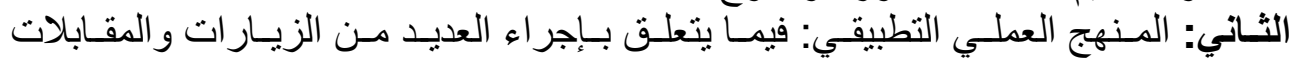

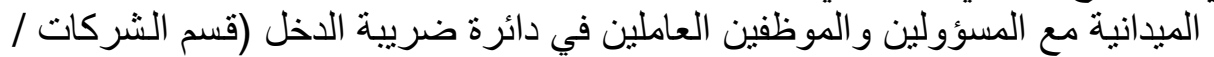

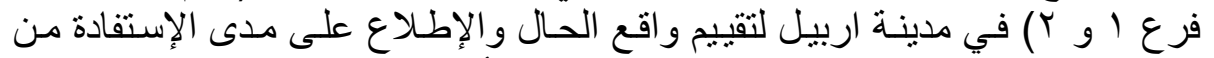

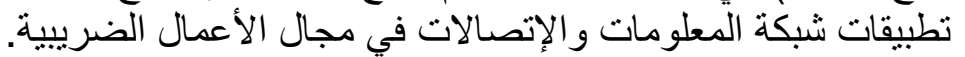

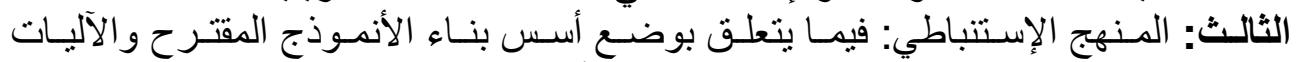

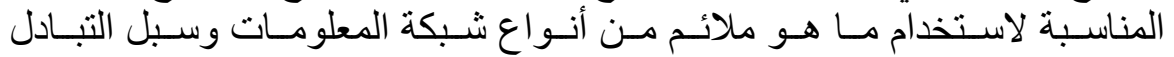

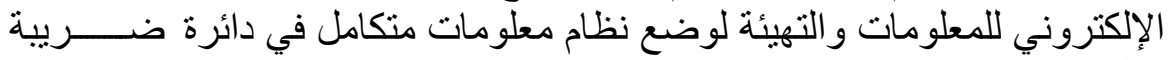

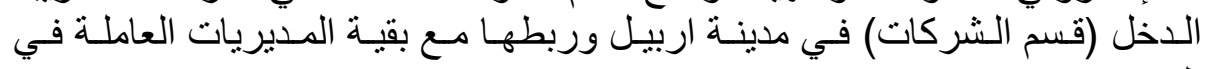
العراق. وسـوف يتم مناقشة وتحليل موضـوع هذا البحث مـن خـلال تقسيمه على المحساور المحور الأول: أسـاليب تقدير الضريبة على الشركات وأهميـة نظـام المعلومـات الضريبي

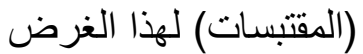

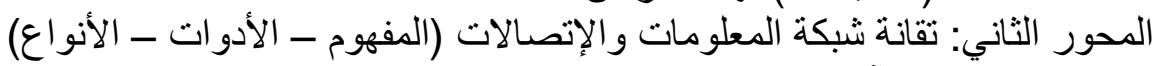

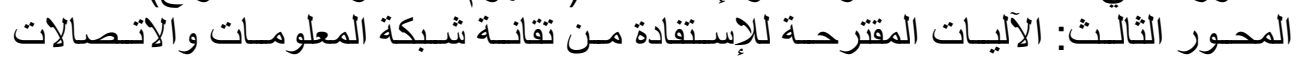
في مجالي حصر المكلفين وتحصيل المعلومات (المقتبسات) عن المكلفين

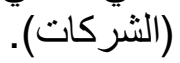

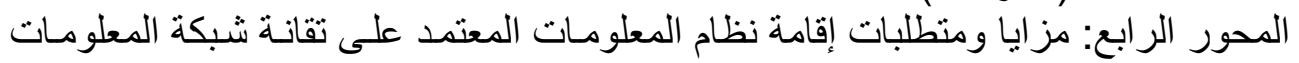
والإتصالات في الدوائر الضرييية (عينة البحث).

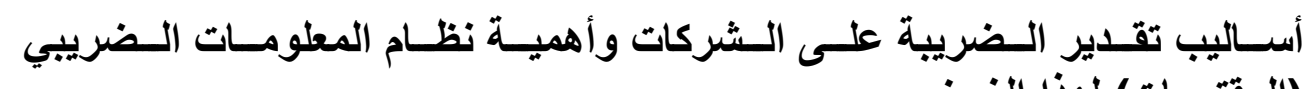

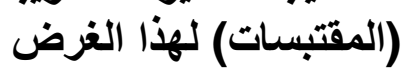

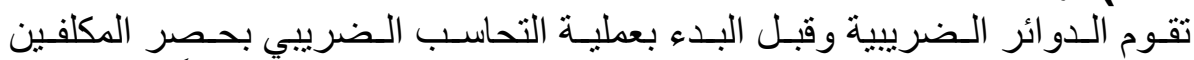

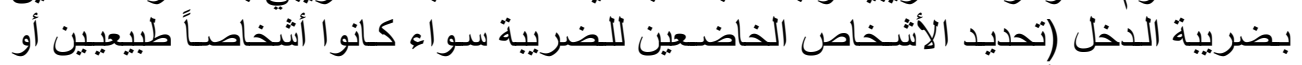

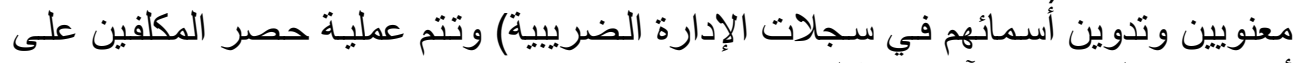

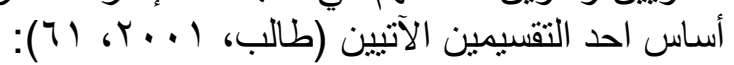

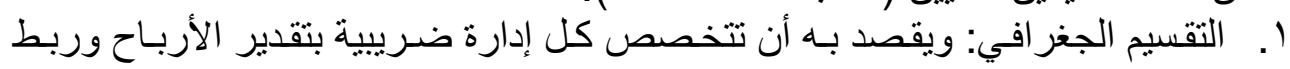

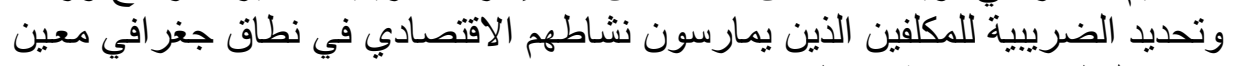

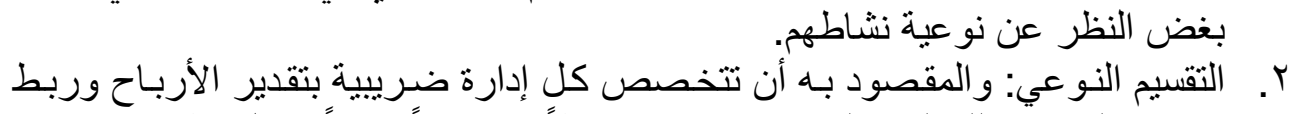

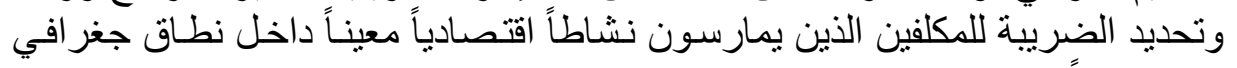
و ومدـا يجبـ الإثـارة إليسه في هذا المقام أن دائرة ضـريبة الدخل (قسم الثركات)

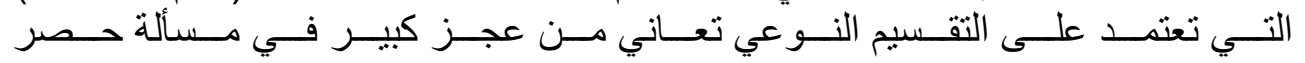




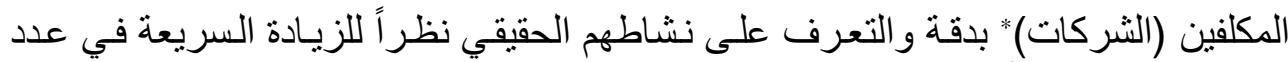

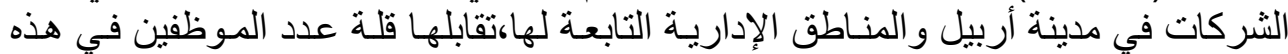

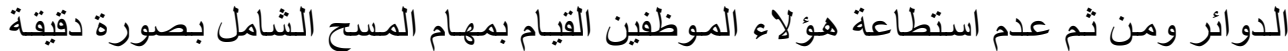

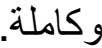

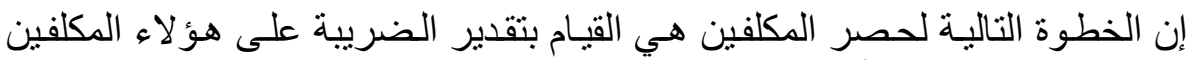

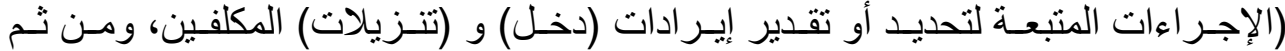
التوصل إلى صـافي الأربـاح أو صـافي الخسائر ومن ثم تحديد مقدار الضريية الناثنئة أو

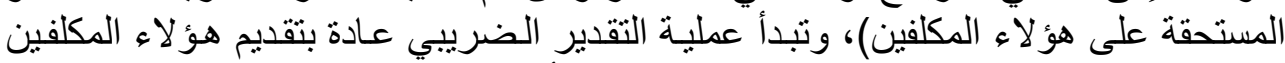

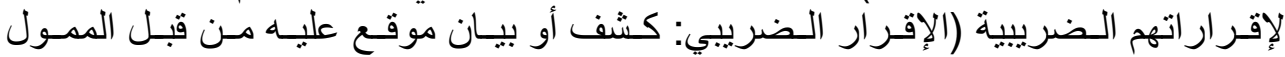

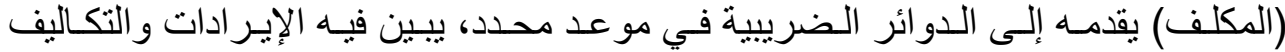

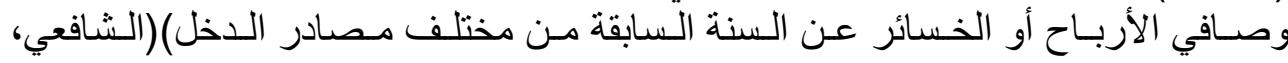

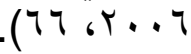

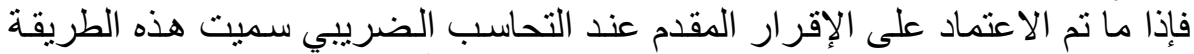

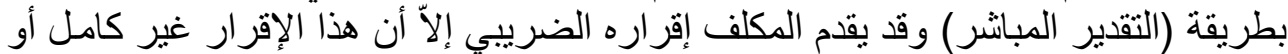

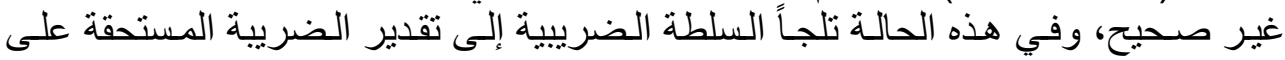

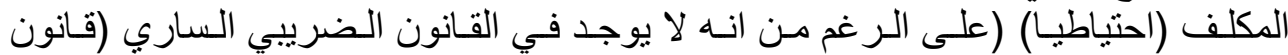

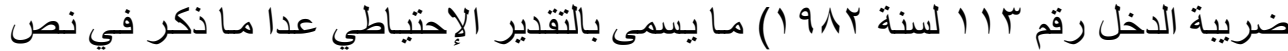

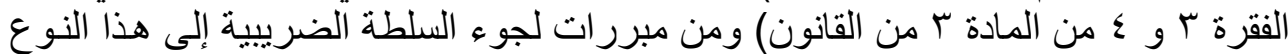
من التقدير: - من

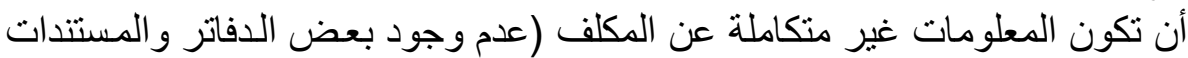
وكتب التأييد الصادرة من الجهات الحكومية أو الجهات الأخرى التي تتعامل معها الشعات الشركة،

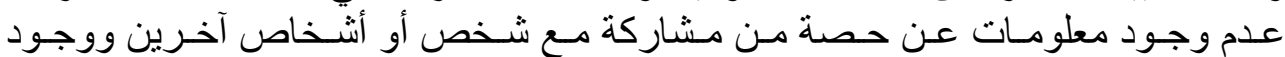

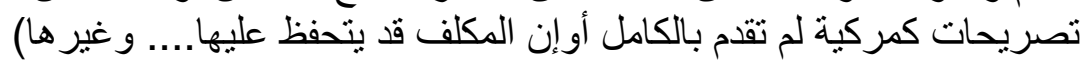

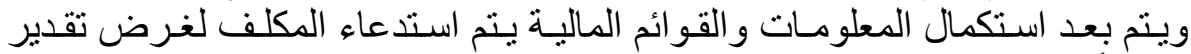

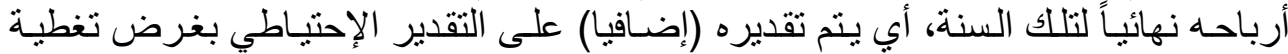
مصادر دخله كافة.

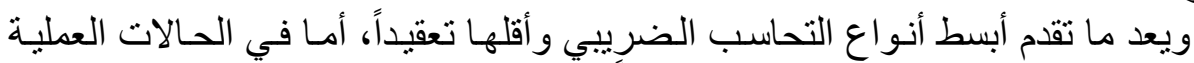

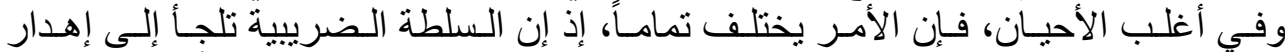

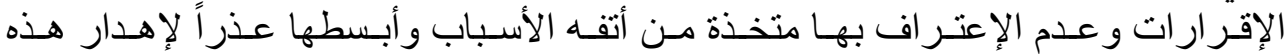
الإقرارات وإهمالها لتلجأ بعد ذلك إلى إلى إدى طر ائق التقدير الآتية:

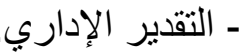
- التقدير الجزافي (الإجتهادي).

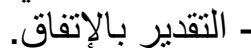

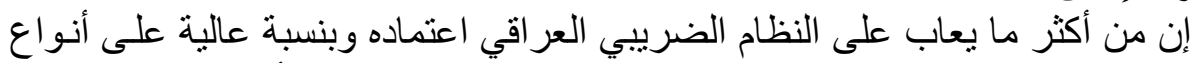
التقدير (الإداري والجز افي) عند التحاسب الضريبي مع الثركات بر غم اعن أن هاتين الطريقتين

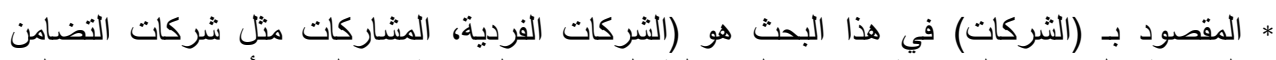

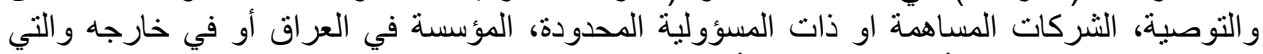
تتعاطى الاعمال التجارية أو لها محل عمل أو مر اقبة في العراق) 


\section{خ خلي}

لا تعتمدان على أسس ومبادئ معروفـة أو موحدة ومنافاتها وابتعادهـا عن العدالـة والدقـة

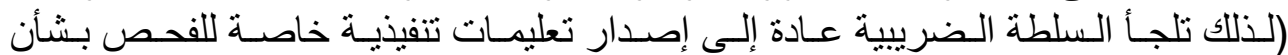

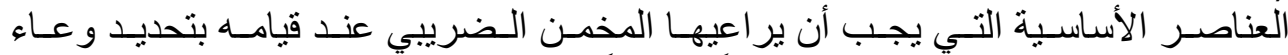

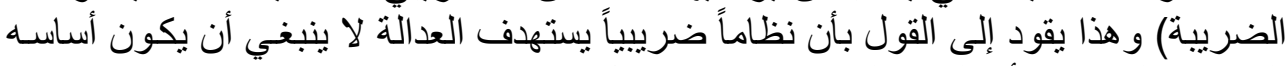

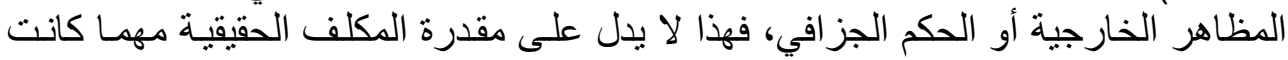
نتائج هذا النوع من التقدير قريية من التقدير الصحيح. ويرى الباحث أن السبب الحقيقي للإعنمـاد على طر ائق التقدير (الإداري والجز الفير)

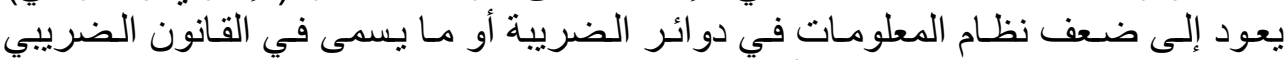

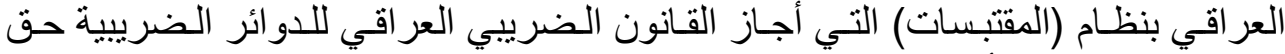

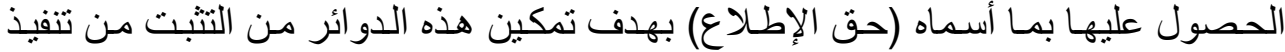

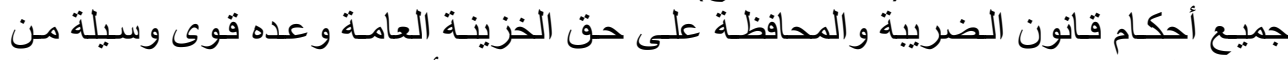

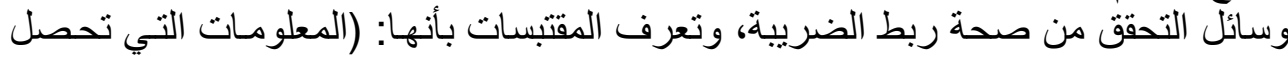

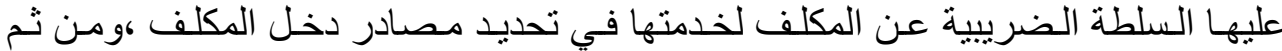

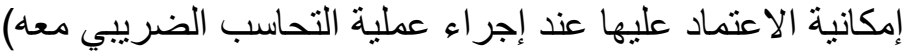
ويمكن الحصول على المقتبسات عن طريق احد المصندات المصدرين الآتيين:

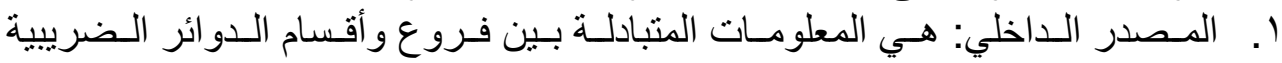

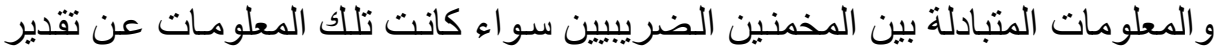
الثركات الفردية أو المشاركات أو الثركات المساهمة أو عن الأرقام التي تظهر عند عند طلب تحليل حسابات المكلفين.

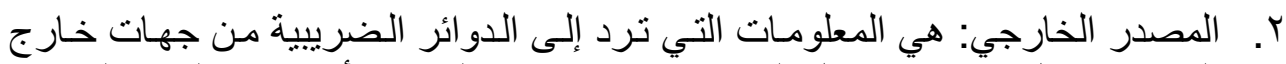

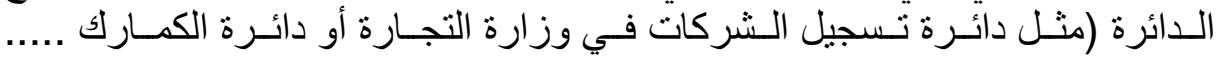

$$
\text { و غير ها). }
$$

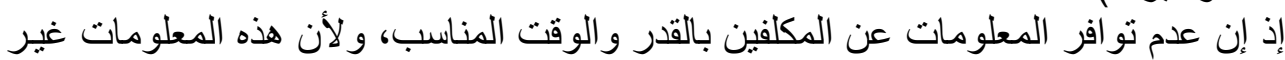

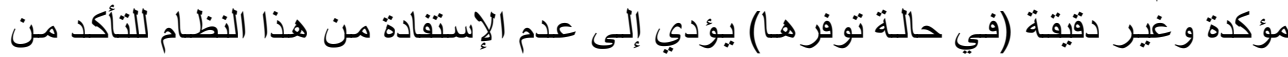

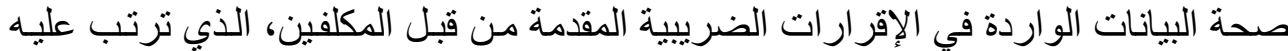

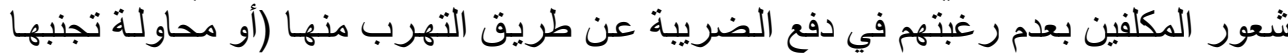

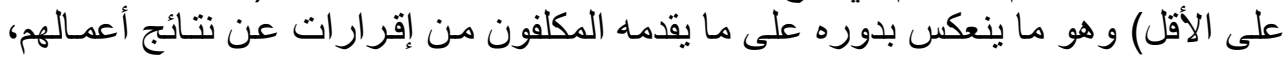

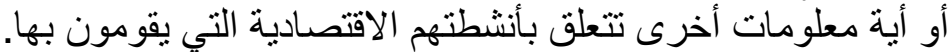

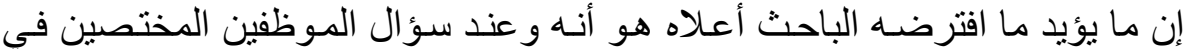

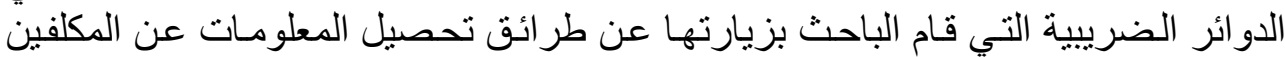

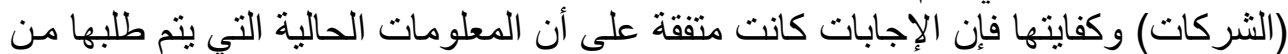

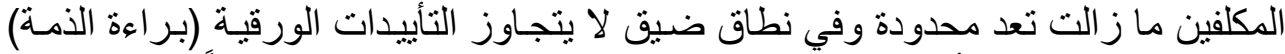

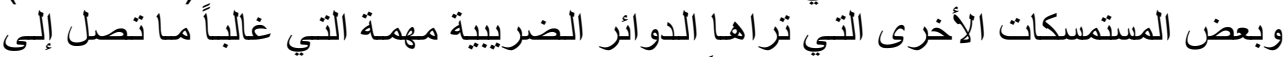

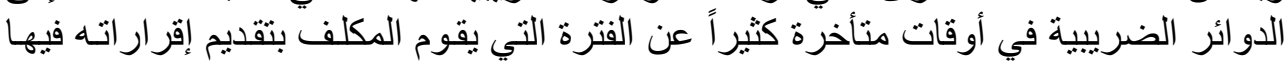

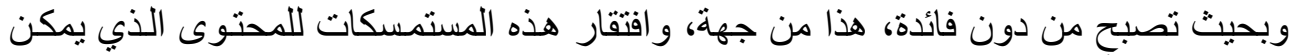

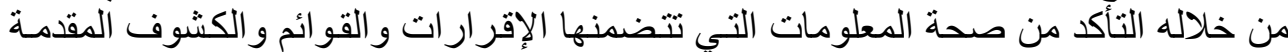
إلى الدوائر الضريبية من جهة الناكن الخرى.

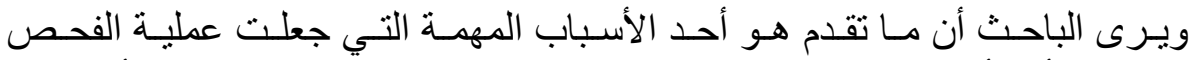

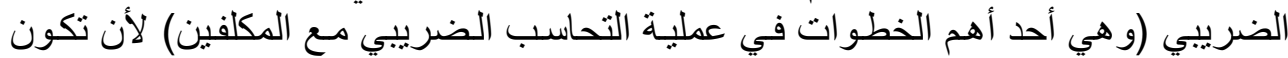




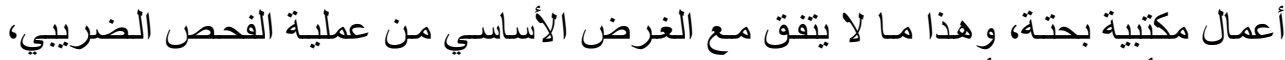

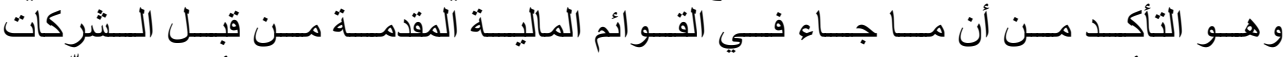

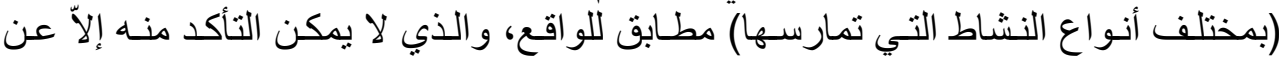
طريق إجر اء الجرد و المعاينة الفعلية.

\section{تقانة شبكة المعلومات والاتصالات}

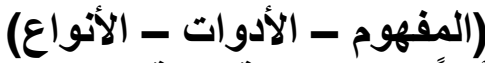

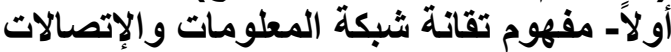

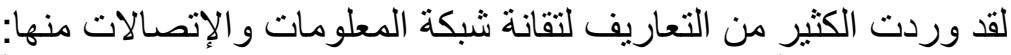

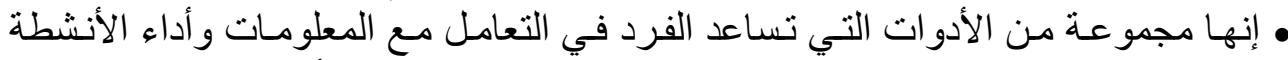

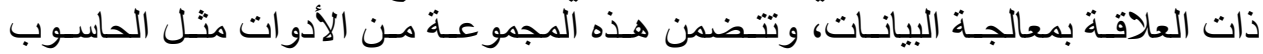

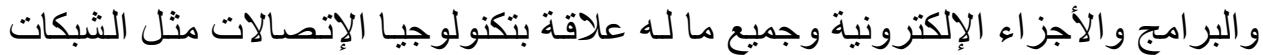

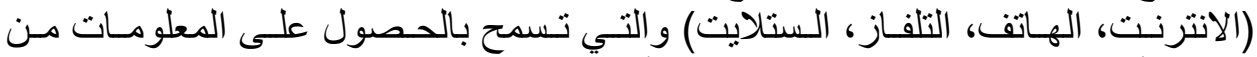

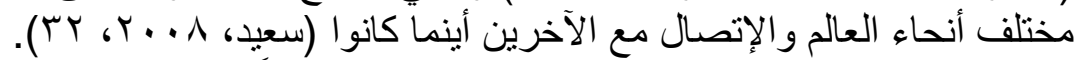

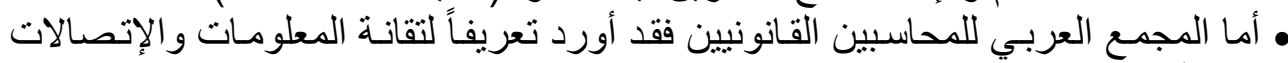

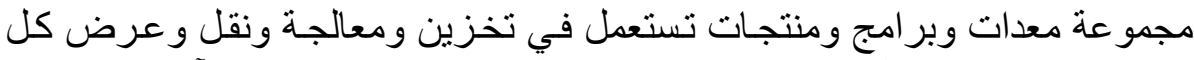
على أنها:

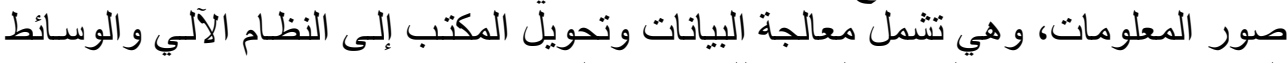

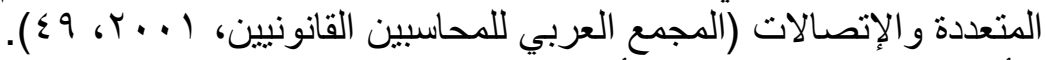

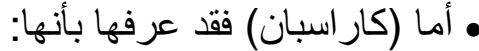

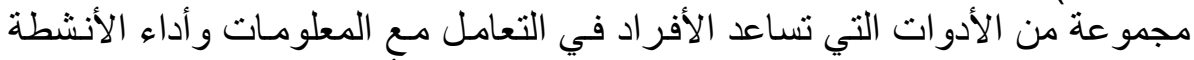

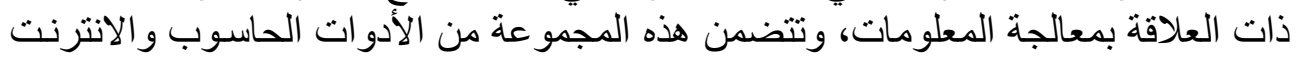

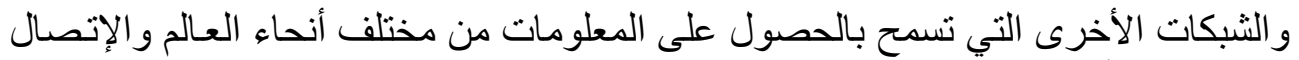

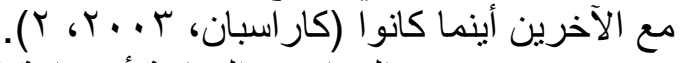

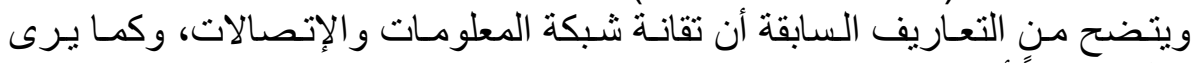

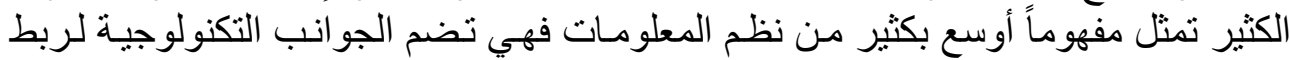

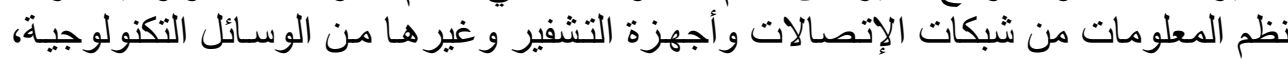

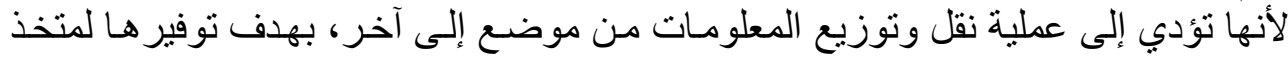

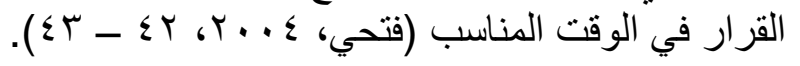

ثانياً- أدوات تقانة شبكة المعلومات والإتصالات

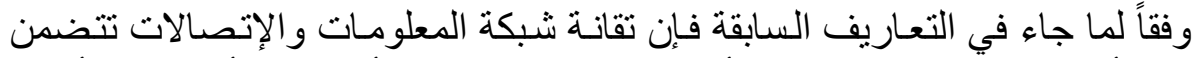

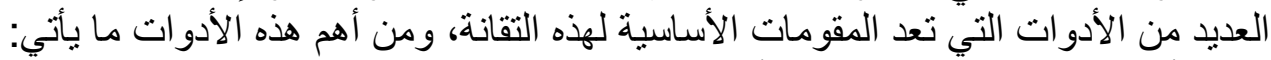

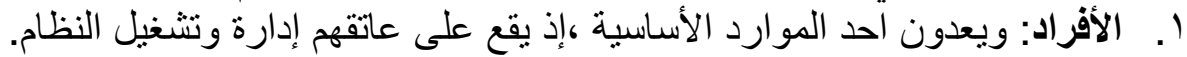

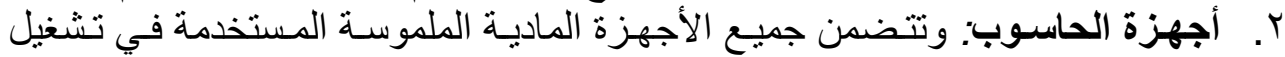

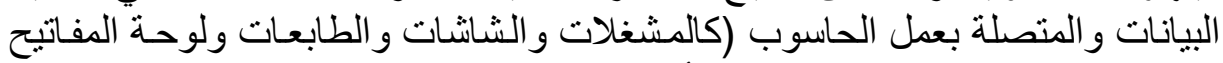

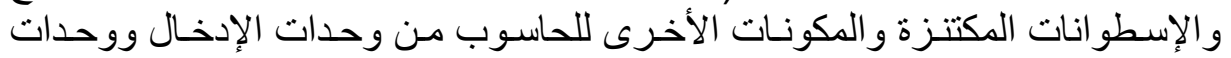
المعالجة المركزية ووحدات الإخر اج ووحدات الإنية التخزين الثانوية). 


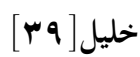

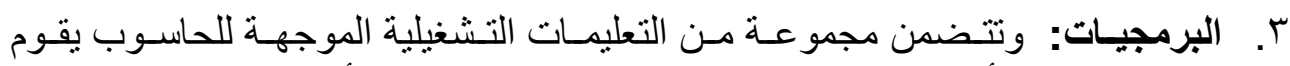

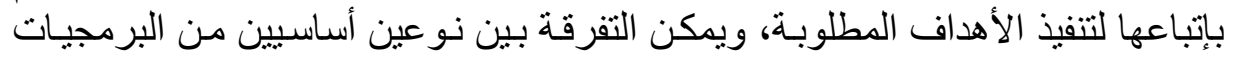

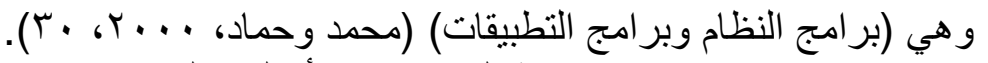

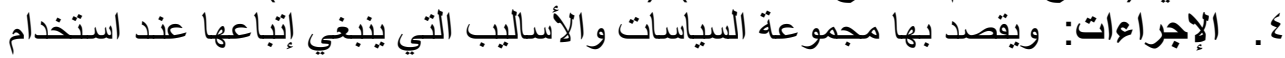

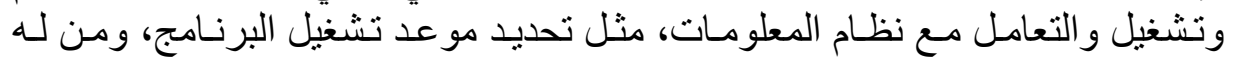

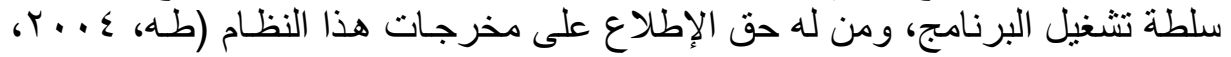
. 0.9

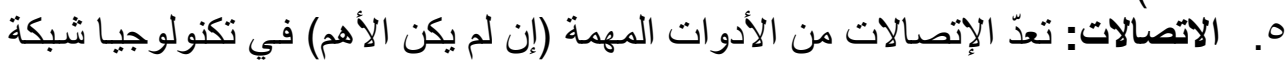

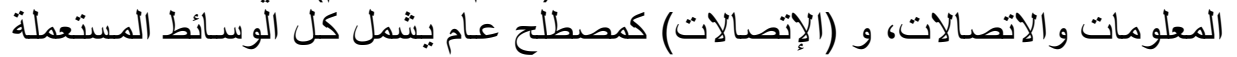

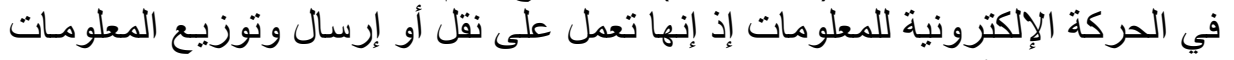

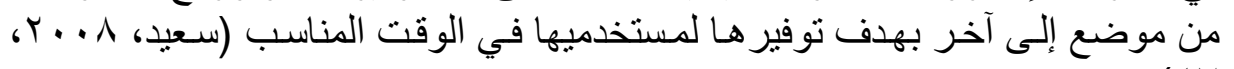

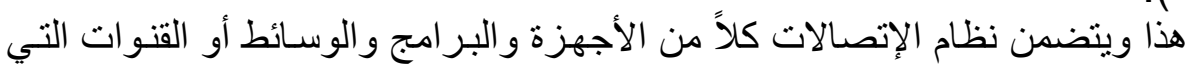

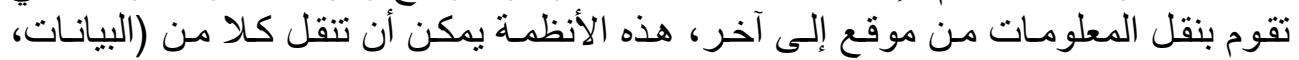

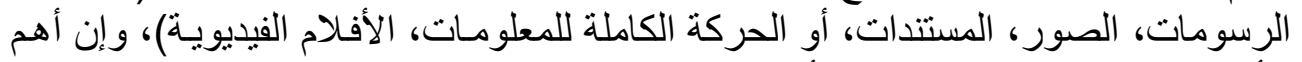
الأجزاء لنظام الاتصالات هو، ما يأتي (Gallegos, 2004, 793).

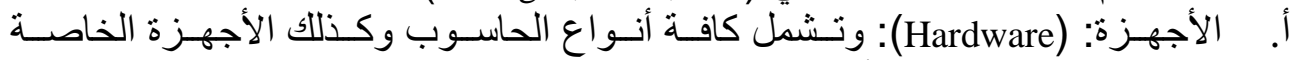
بالإتصالات (Modems) أو الحاسوب الصغير و المخصص للإتصالات البطيئة. ب. ناقل (وسيط) الاتصالات (Communication media)

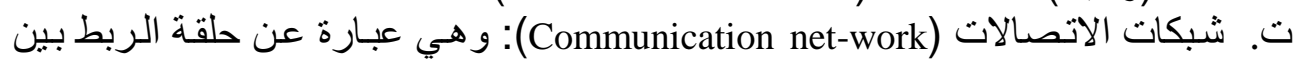

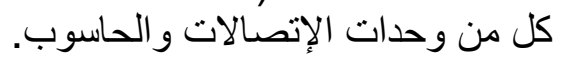

ث. الإتصالات المعالجة (Communication processors).

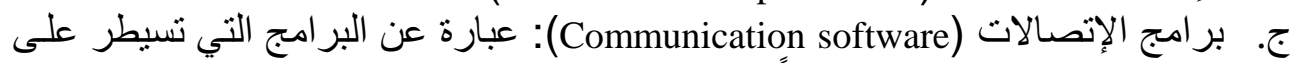

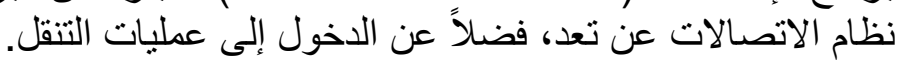

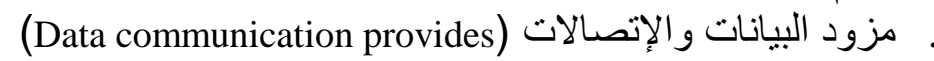

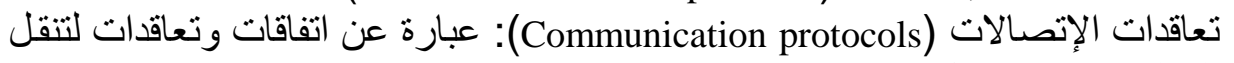

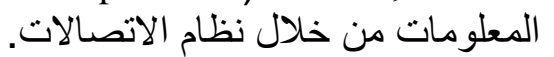

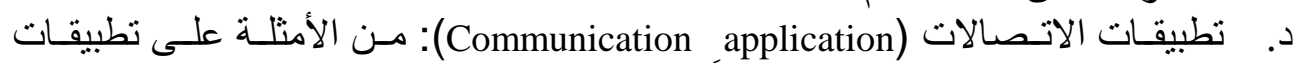

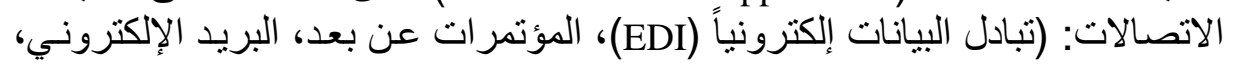

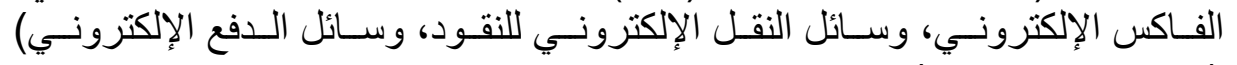
.(Turban, 2003, 165) 7. . الثبكات (Net-works)

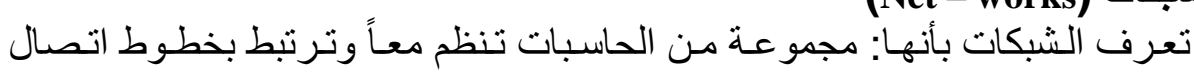

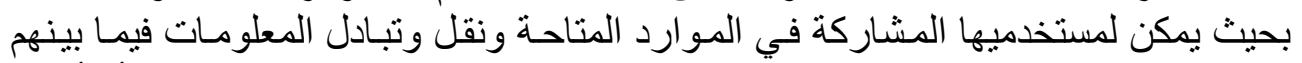

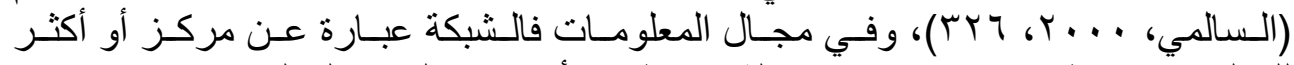

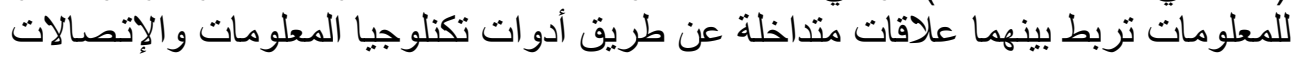

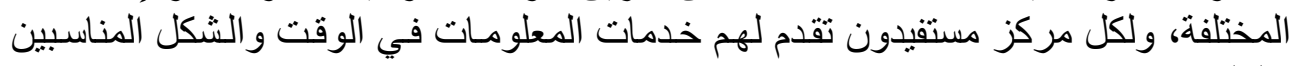

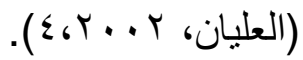




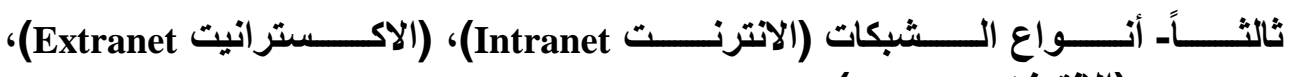
(الانترنت اعتواع) (Internet) 1. الانترنت (Intranet)

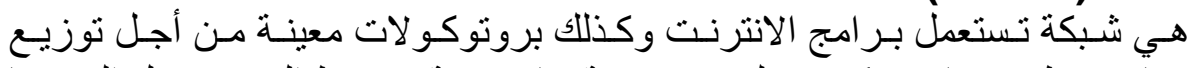

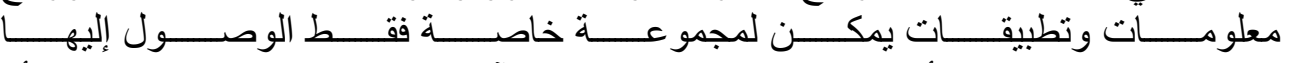

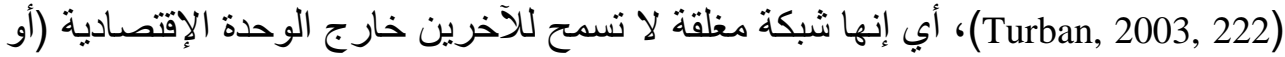

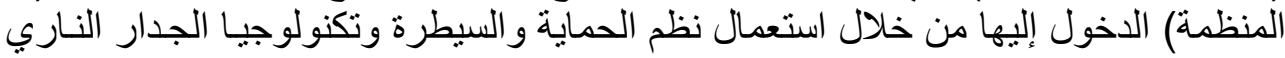
(Fire wall)

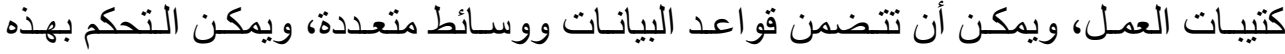

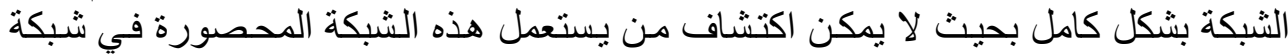

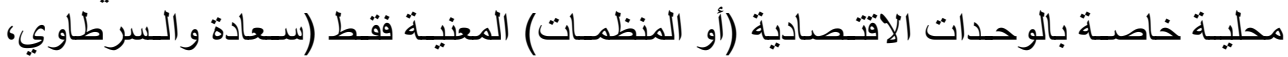

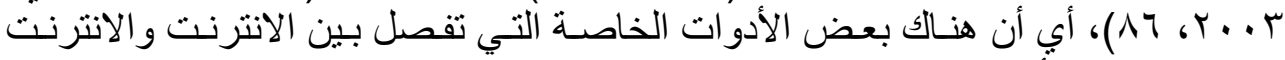

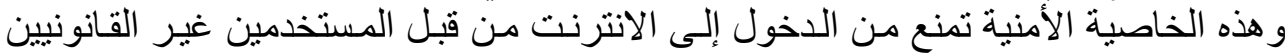

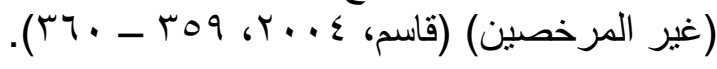

(Extranet) (الإكسترانيت

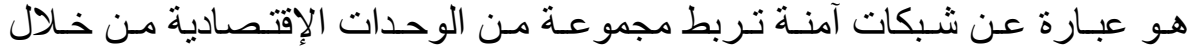

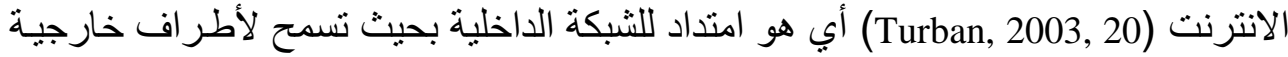

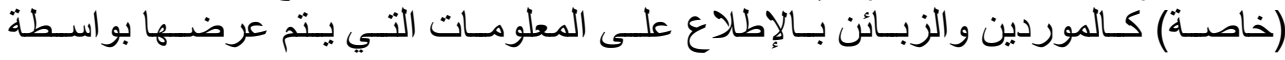

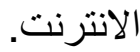

وتوفر شبكات الإكستر انيت الأمن المطلوب داخل الشبكة لتبادل المعلومـات الخاصـة

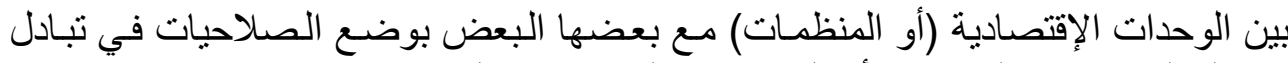
هذه المعلومات بين الوحدات (أو المنظمات) المرتبطة بعملها فقط.

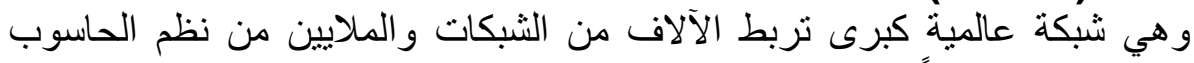

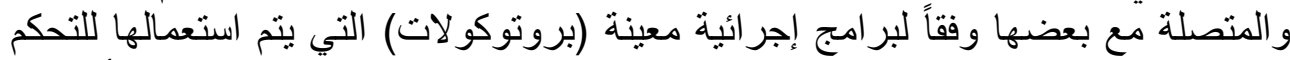

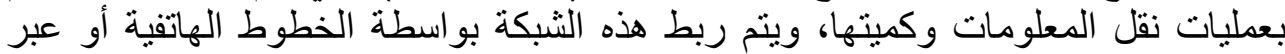

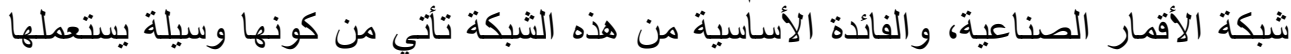

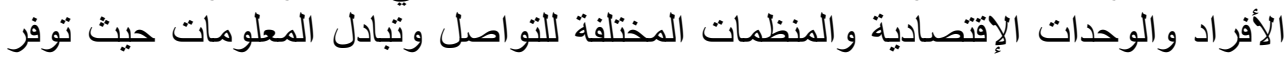

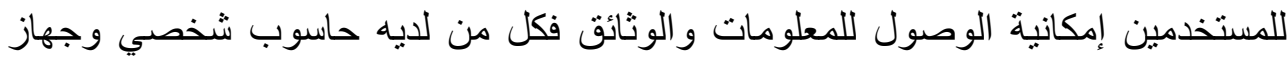

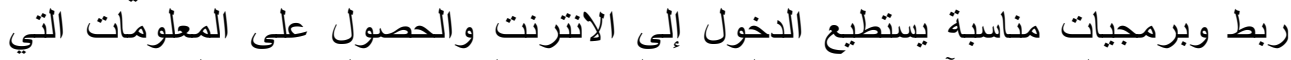

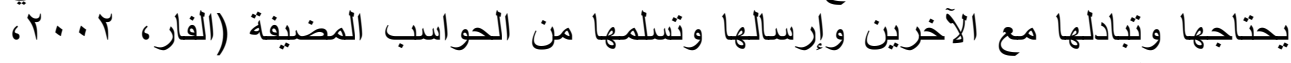

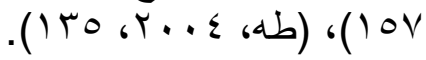

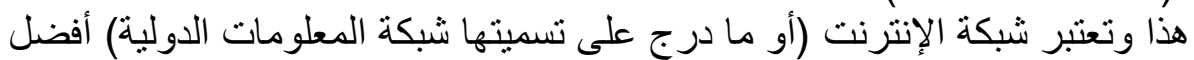

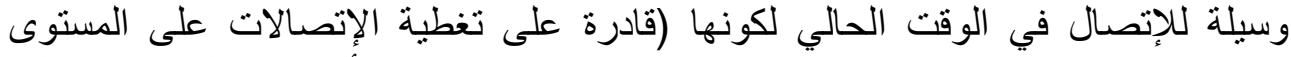
العالمي، وكلفة تشغيلها المنخفضة وإمكانية ارتباطها مع مختلف الأجهزة (كالهو الهي التف النقالة، أجزةة التقاط البث الفضائي التلفزيوني)). 
الآليات المقترحة للاستفادة من تقانة شبكة المعلومات والإتصالات في مجالي حصر المقري

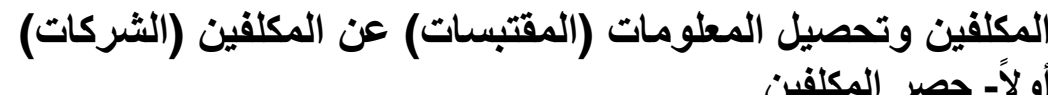

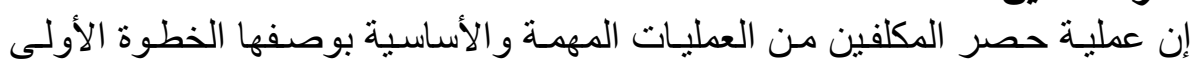

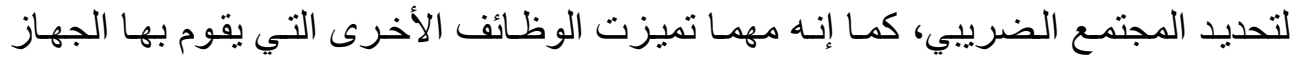

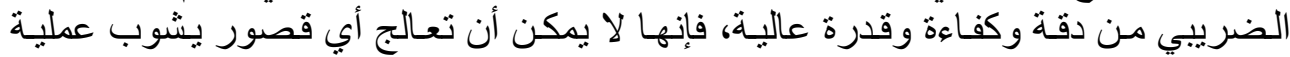

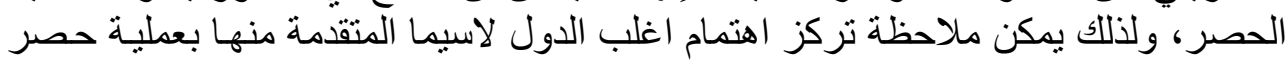
المكلفين وتفنتها في استخدام أفضل الوسائل و أكفئها بغية تحقيق النجال النجاح في أداء هذه المهمـة

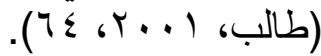

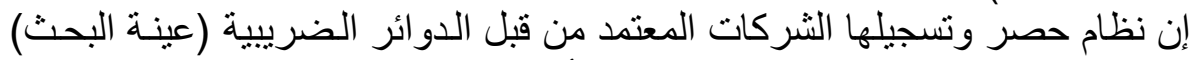

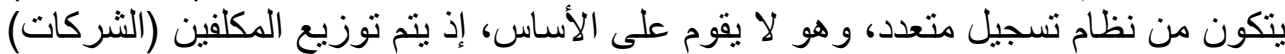

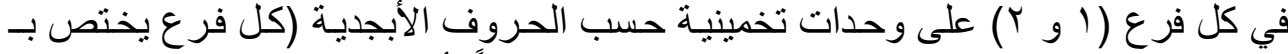

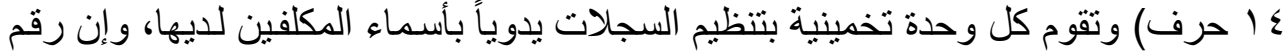

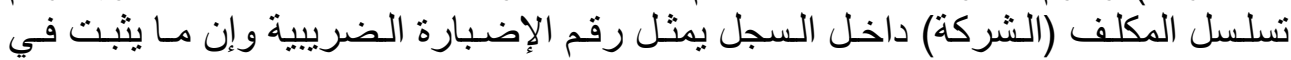

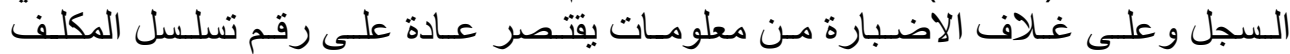

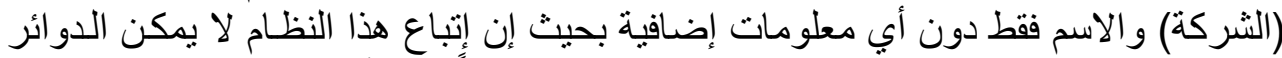

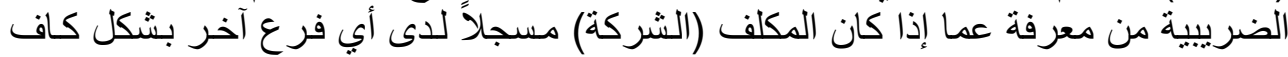

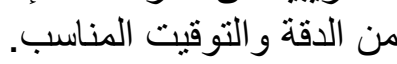

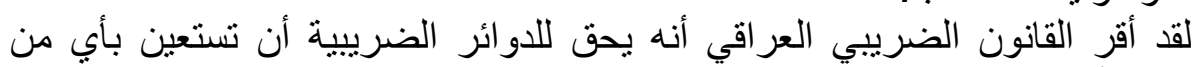

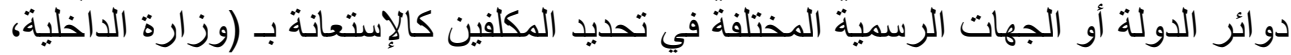
وزارة المالية، وزارة التجارة والصناعة، دائرة مسجل الثركات التئل في وزارة التجارة، ديوان

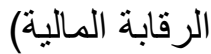

و هنا برى الباحث إمكانية استخدام شبكات المعلومات و الإتصالات في هذا المجال المبال

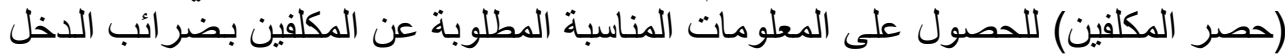

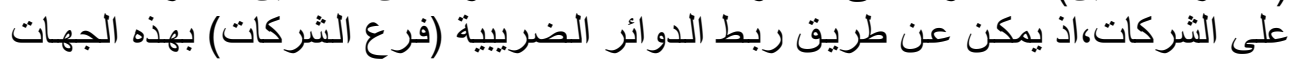

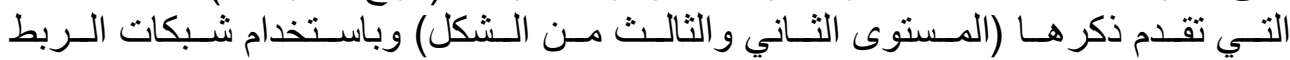
(الاكستر انيت) الحصول على المعلومات الاتية عن المكلفين:

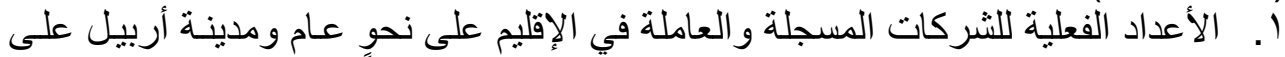

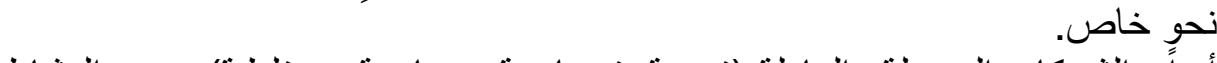

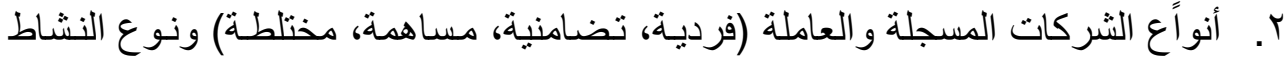

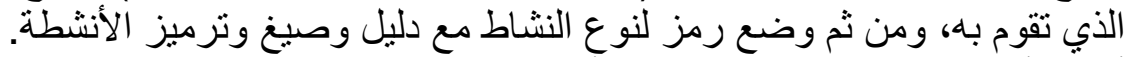

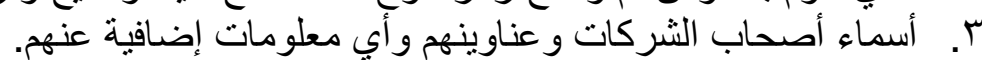

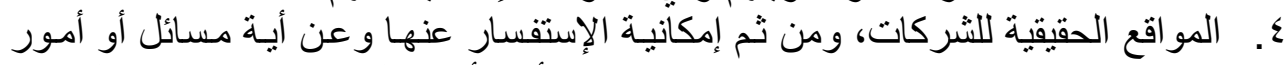

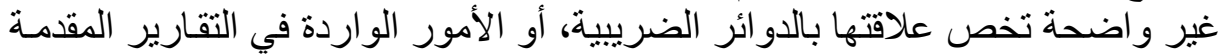

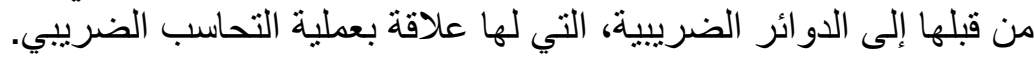

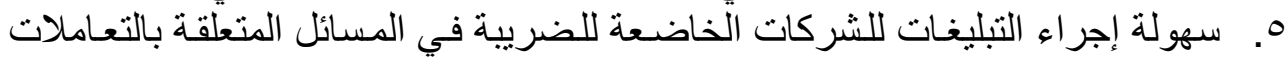
الضريبية.

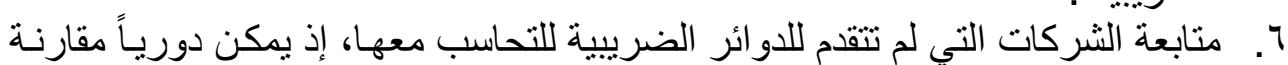

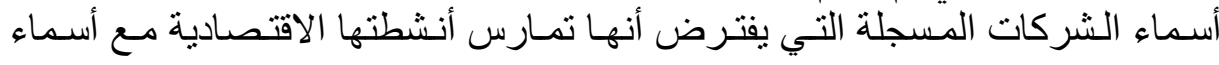




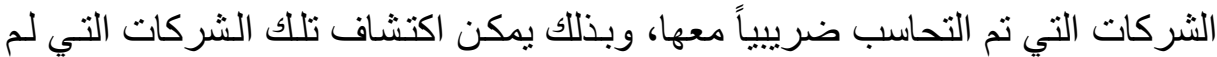

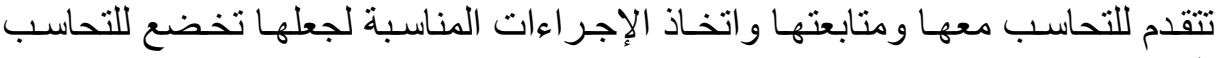

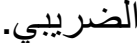

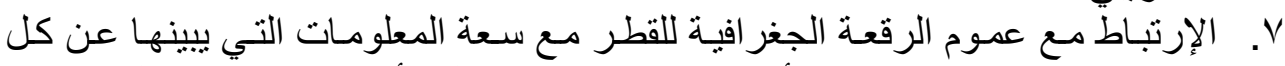

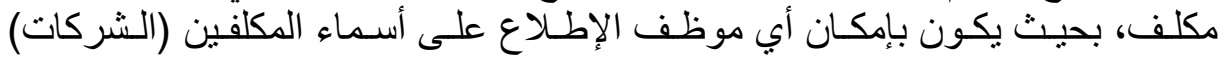

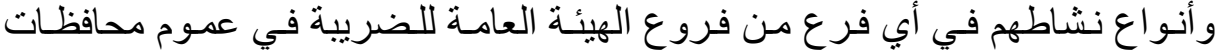

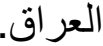

إن ما يبرر استخدام شبكة الربط (الاكسترانت) أنها تتمتع بمزية السرية والإقتصار

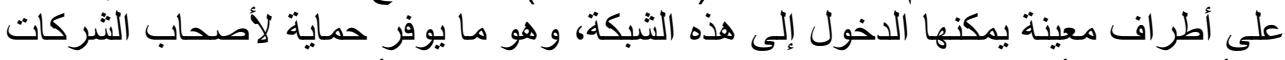

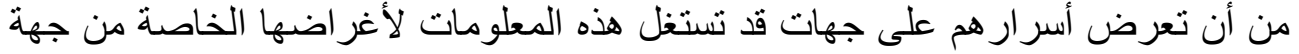

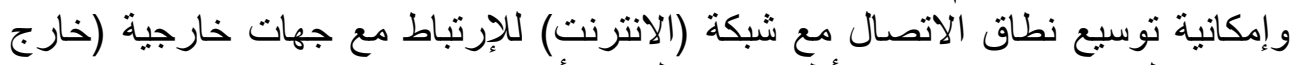
حدود الإقليم) سواء كانت هذه الأطر اف في العر اق أو أو خارجه.

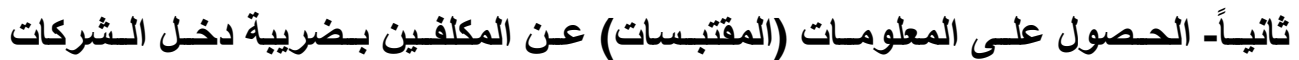

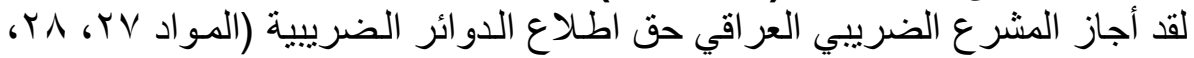

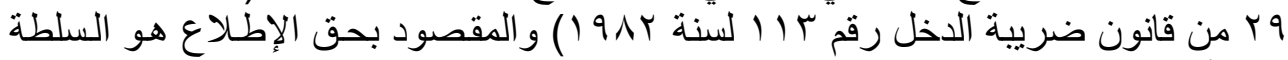

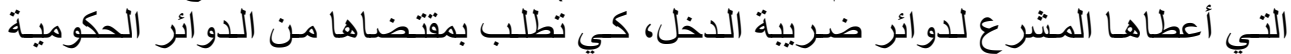

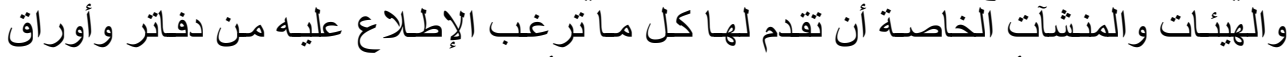

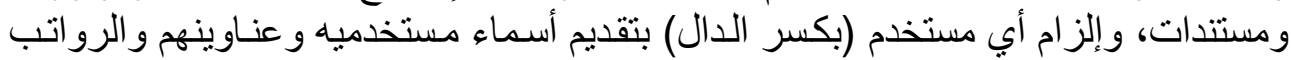

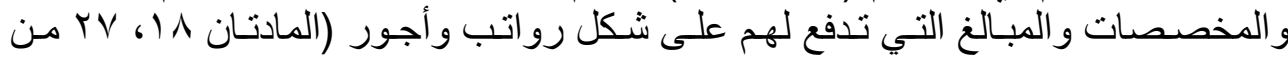

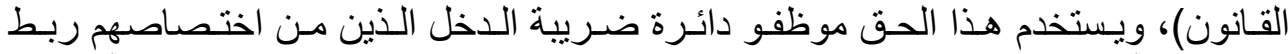

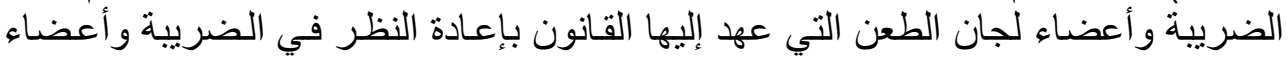
لجان الاستئناف.

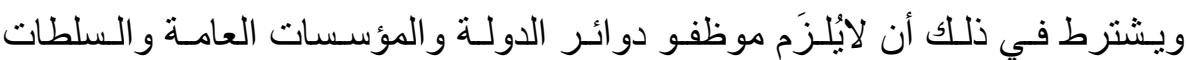

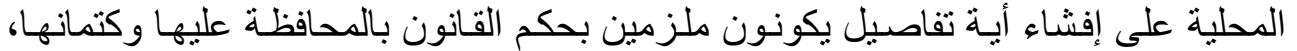

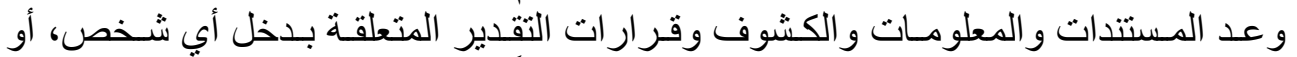

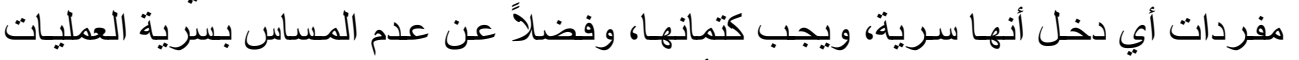

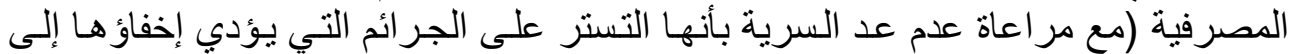

$$
\text { إلحاق الضرر بالصالح العام). }
$$

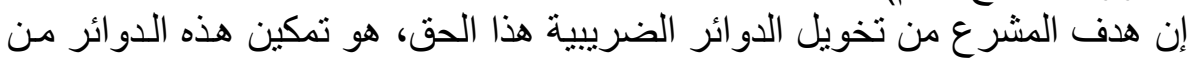

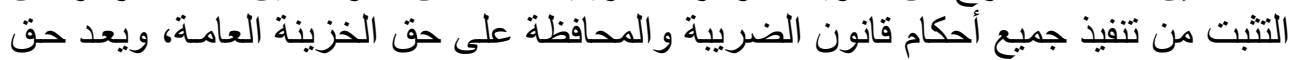

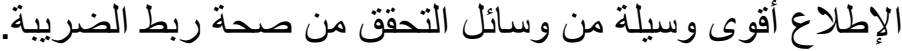

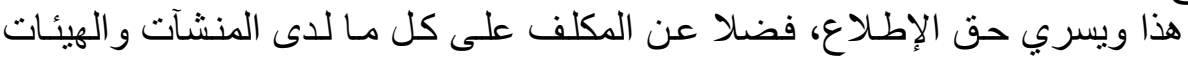

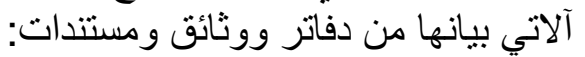

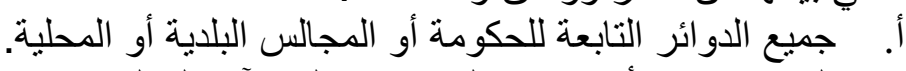

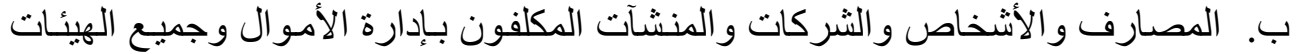

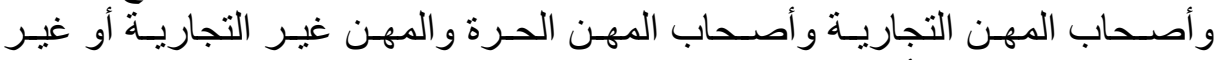

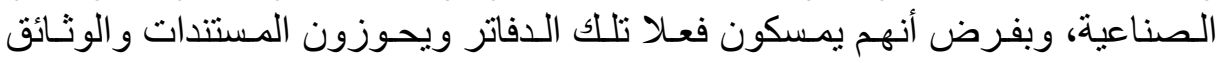




\section{خ خلي[r]}

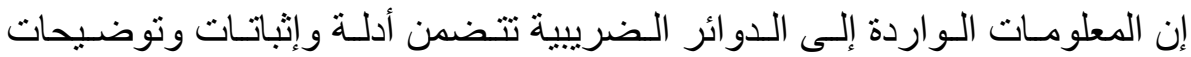
و إخباريات عن المكلفين وأنشطتهم الإقتصادية للمساعدة بالوصول إلتى المى المكلفين (الشركات)

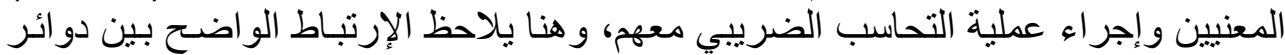

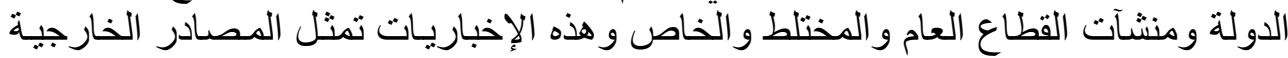

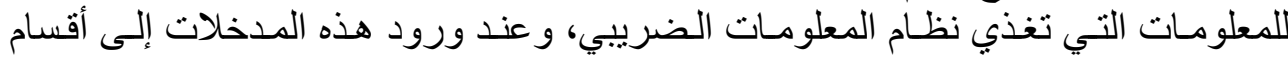

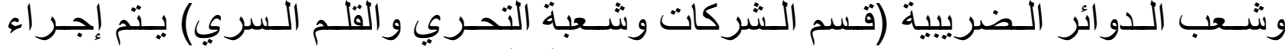

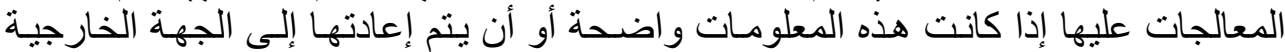

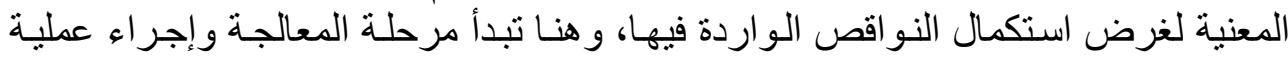

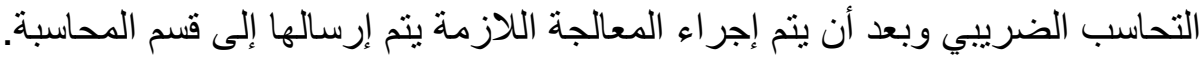

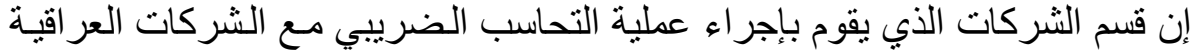

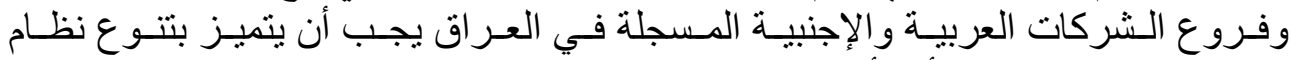

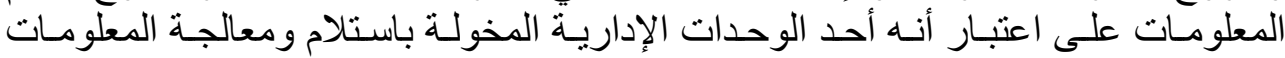
الداخلة إلى قسم المحاسبة.

إن الإطلاع على الو اقع الفعلي لدوائر الضريية (عينة البحث) يشير إلى عدم إنسيابية

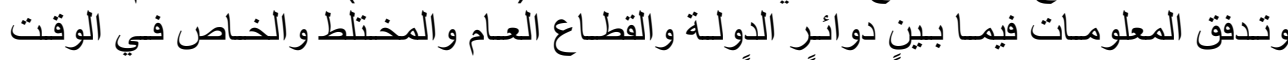

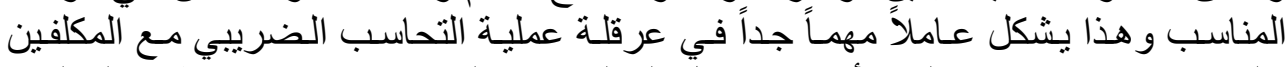

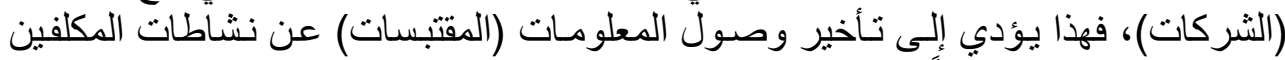

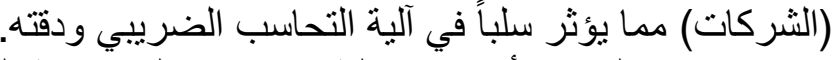

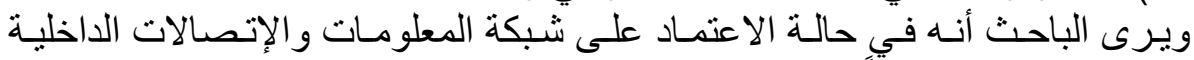

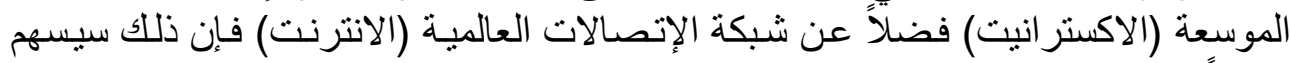

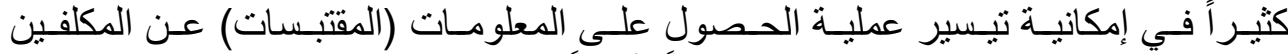

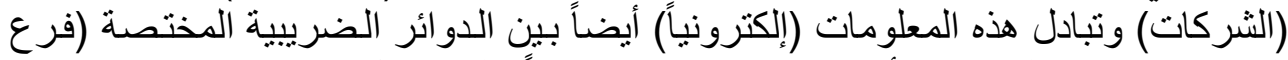

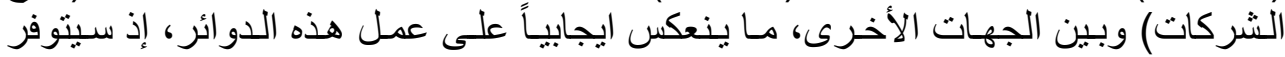

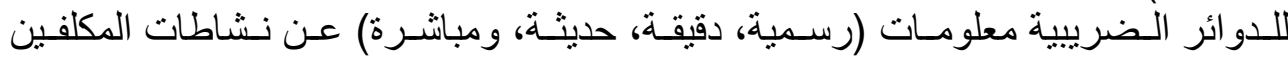

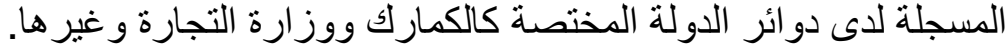

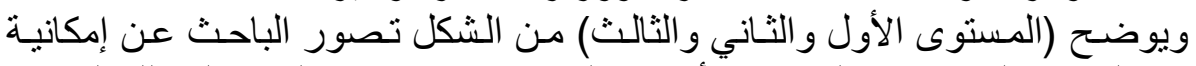

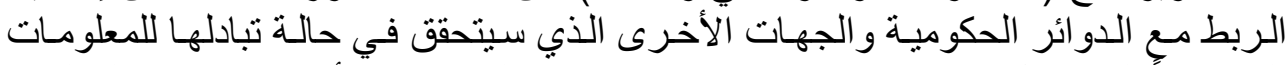

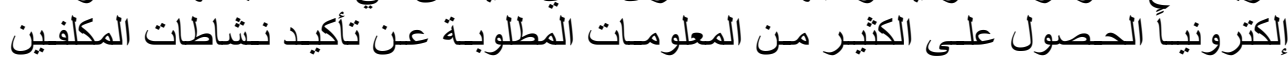

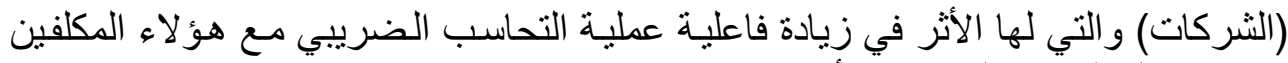

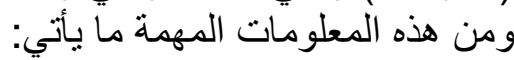
ا. طلب تأكيد المعلومات الواردة في الإقرار التهات الضرات الضريبية التي تقدمها الشركات المكلفة

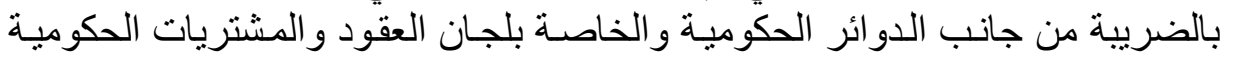

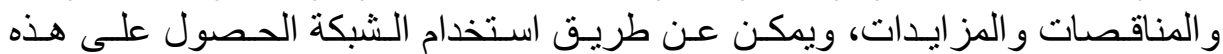

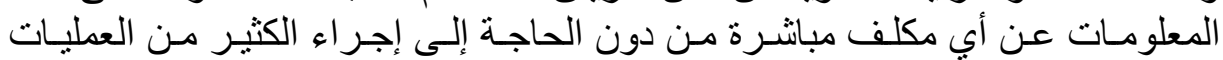

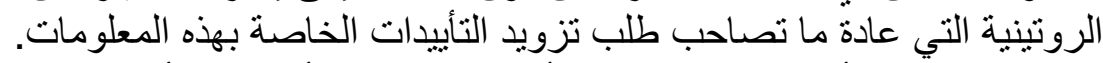

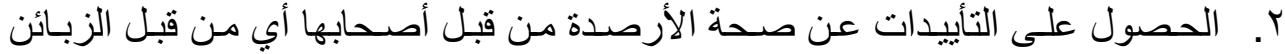

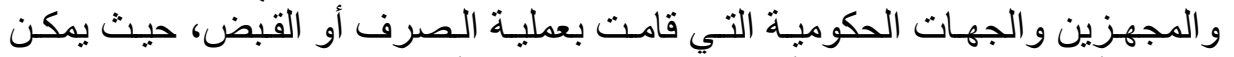

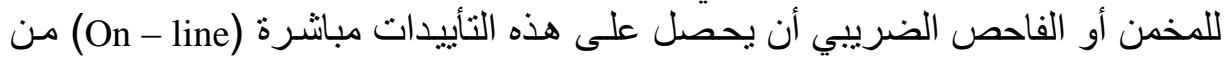

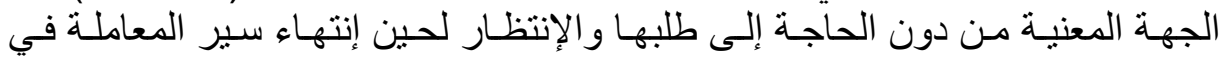




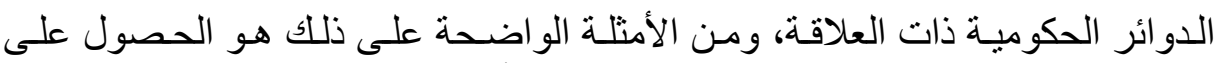

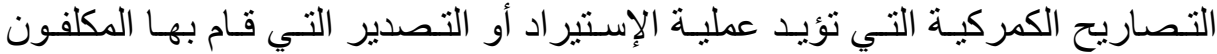

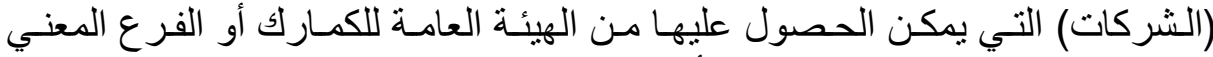

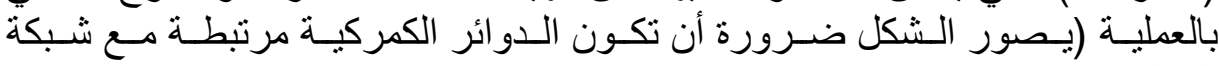
المعلومات الخاصة بالدو ائر الضريبية).

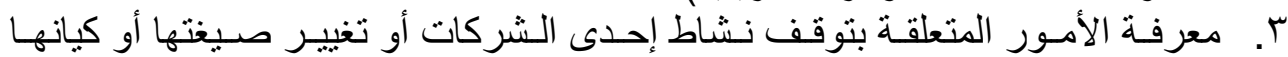

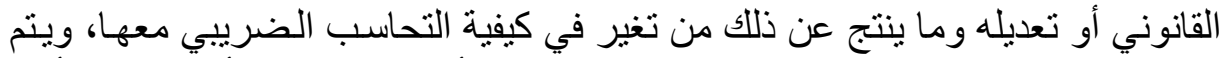

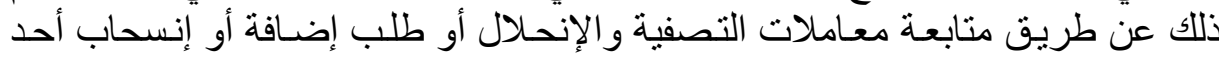

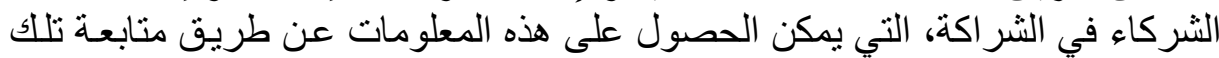

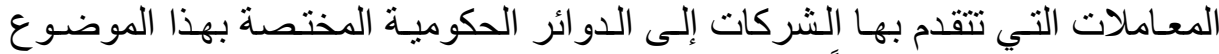

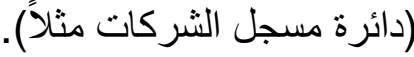

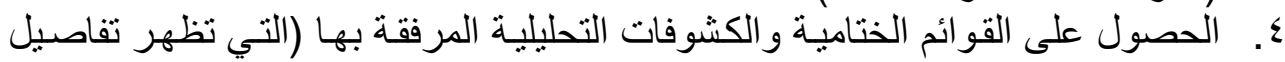

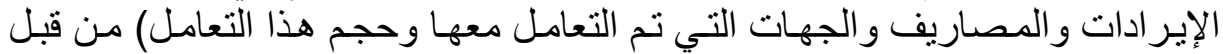

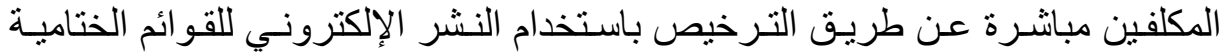

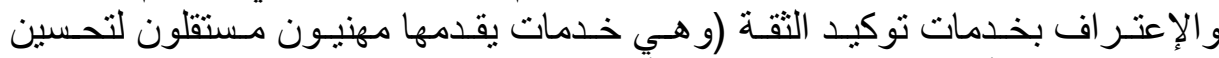

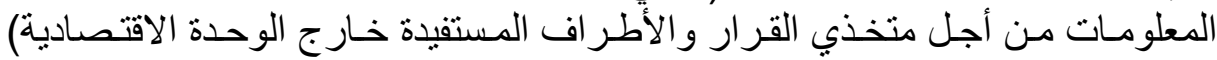

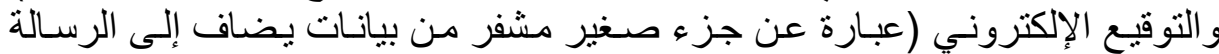

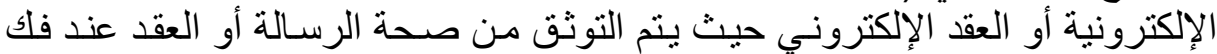

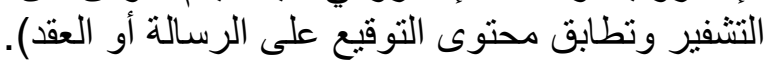

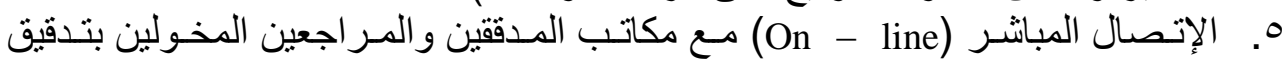

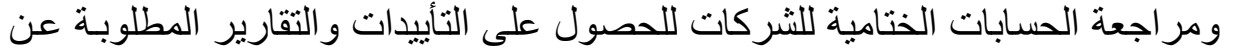

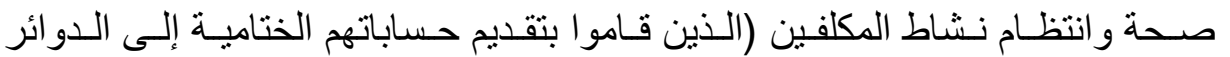

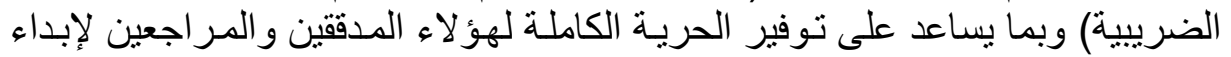

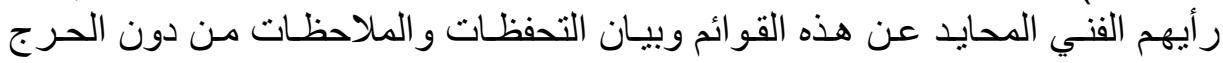

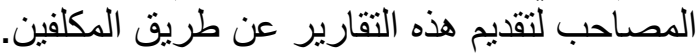

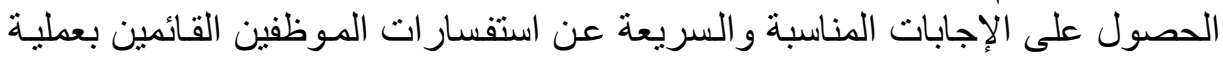

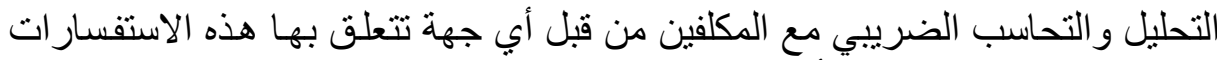

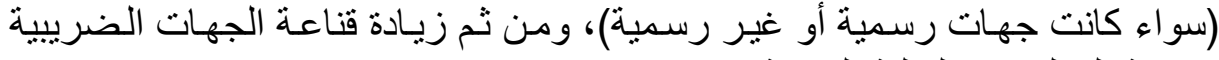
بسلامة المعلومات المالية المقدمة.

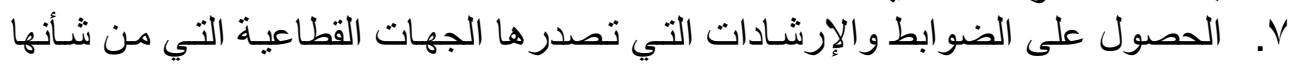

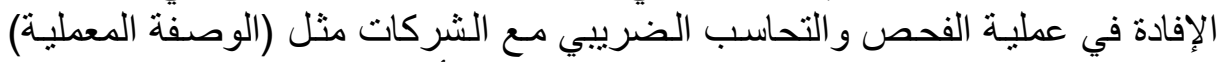

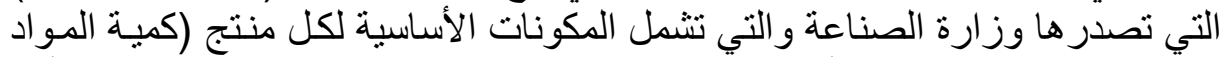

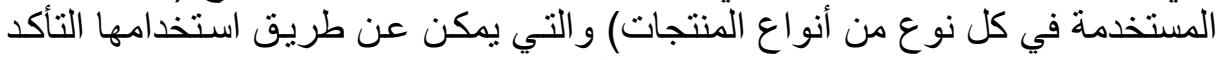

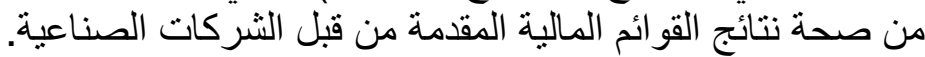

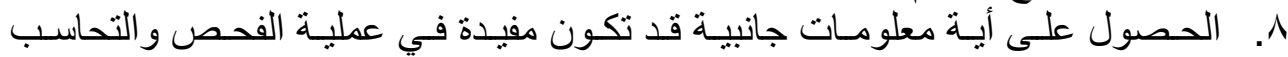

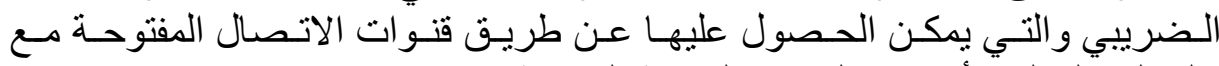
(البنوك، المكلفين أنفسه، الجهات الرقابية الرسمية). 


\section{خ خلي[0]}

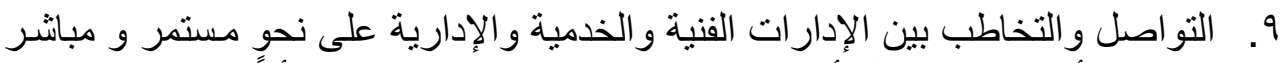

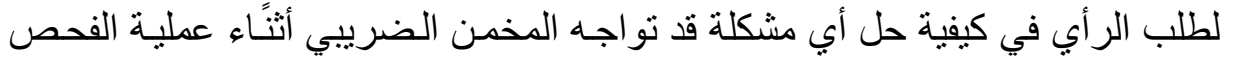
و التحاسب الضريبي مع المكلفين.

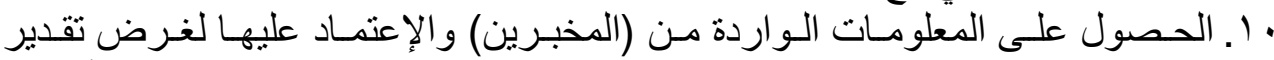

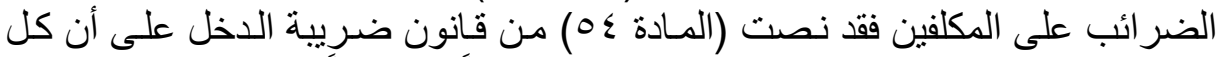

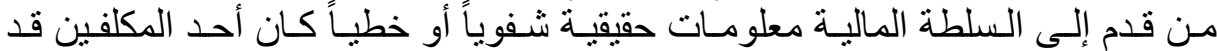

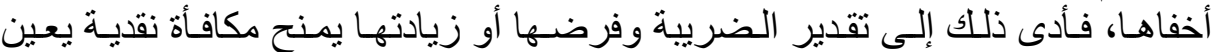

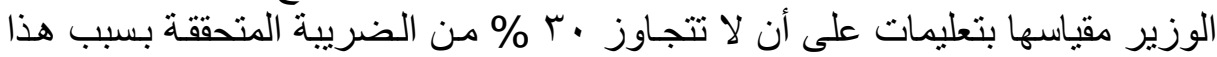

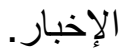

و الشكل الآتي يوضتح تصور ات الباحث عن كيفية ربط الدوائر الضريبية بشبكات

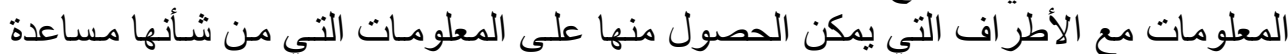

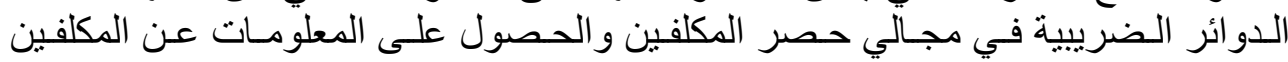




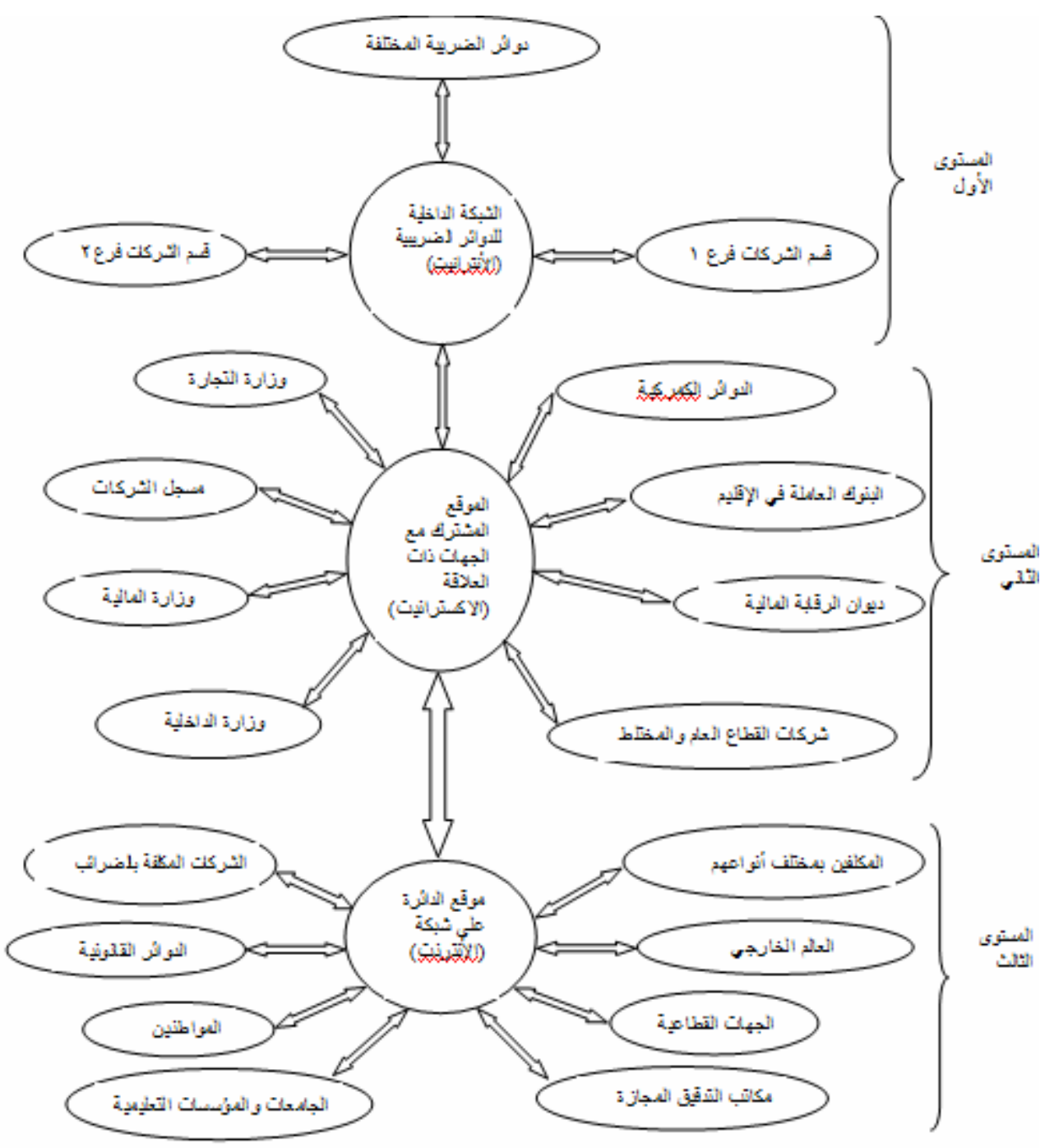

الشكل المبكور

مستويات ارتباط دوائر الضريبة بأنواع شبكة المعلومات والإتصالات مع الأطراف الداخلية

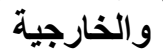

المصدر: الثكل من إعداد الباحث.

ويرى الباحث أن الخطوة الأولى والأساسية لتفعيل تطبيق الآلية المقترحسة هي إنشاء

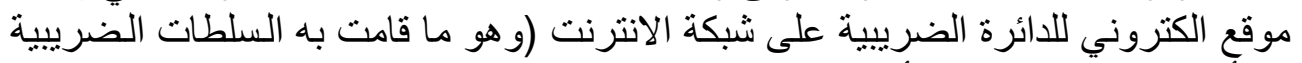

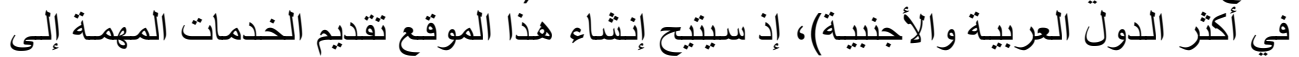

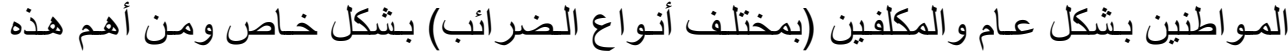

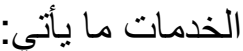

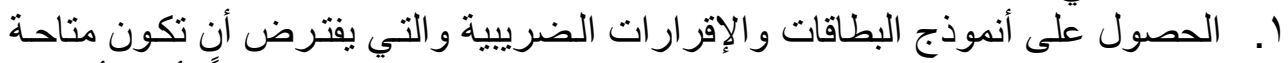

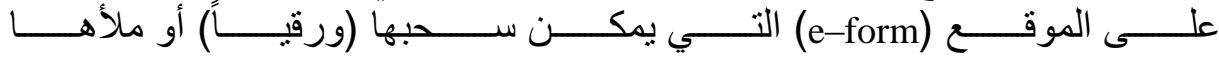


(إلكترونياً)، و هذا ما يضمن أنه سيتم ملء البطاقة أو الإقرار الضريبي بصورة سليمة من وجهة نظر الدو ائر الضريبية.

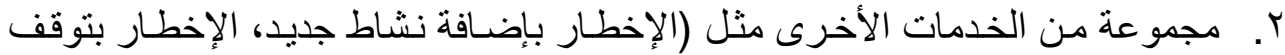

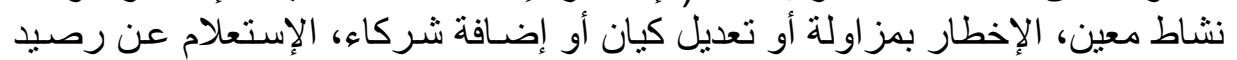

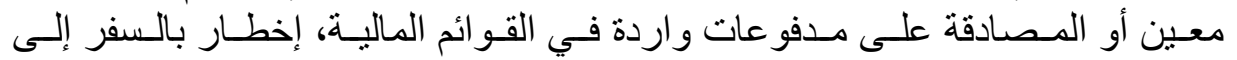

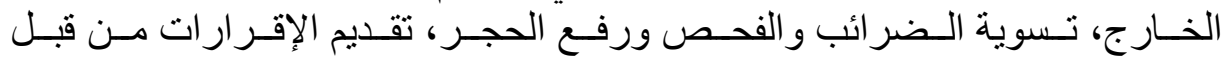

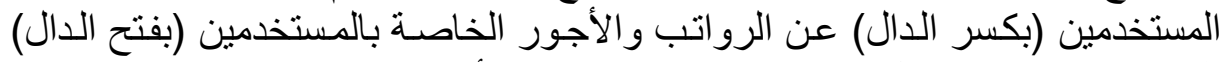

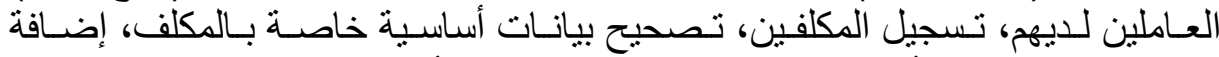

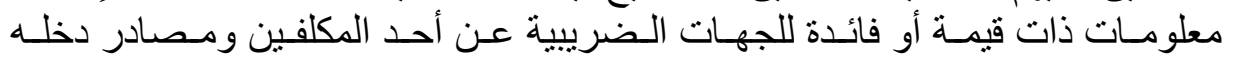

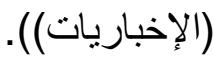
ويمكن تقسيم الخدمات التي يقدمها الموقع على ثلاثة مستويات:

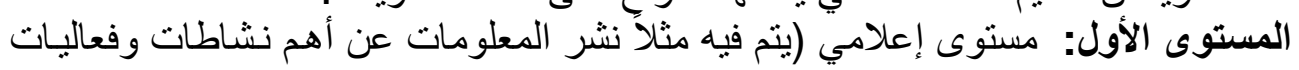

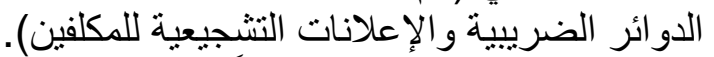

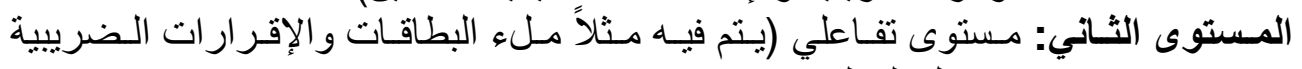
من قبل المكلفين).

المستوى الثالث: مستوى معاملاتي (ويتم فيه مثناً دفع المستحقات الضرينة فيبة).

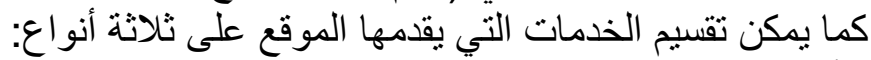

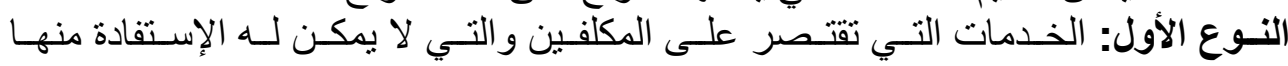

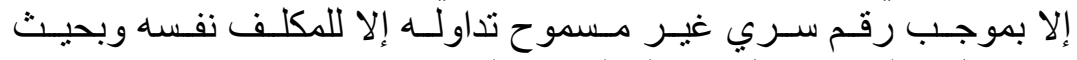

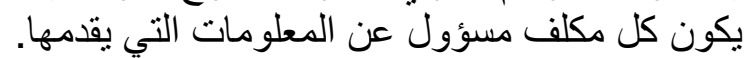

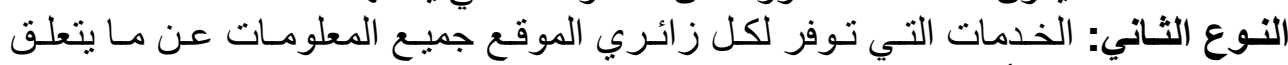

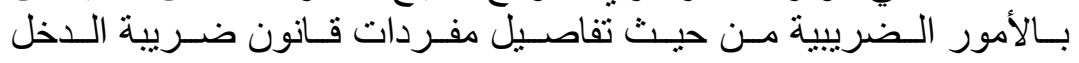

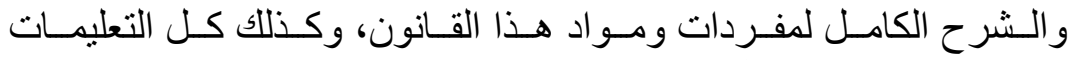

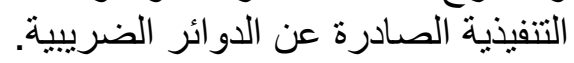

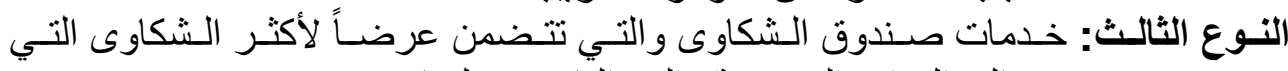
ترد إلى الدوائر الضريبية والت الرد القانوني عليها.

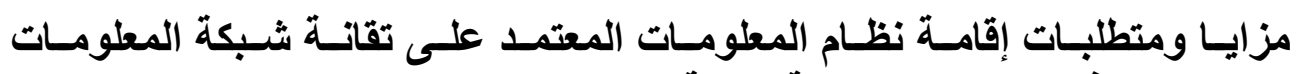

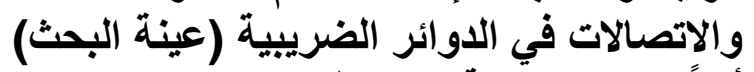

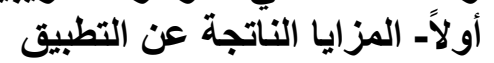

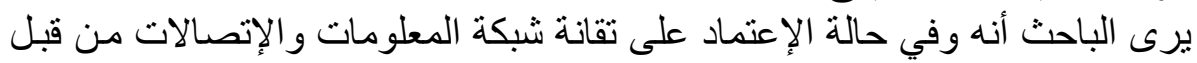

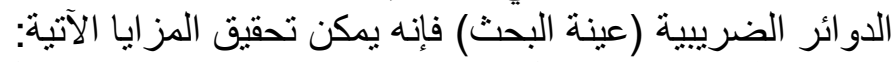

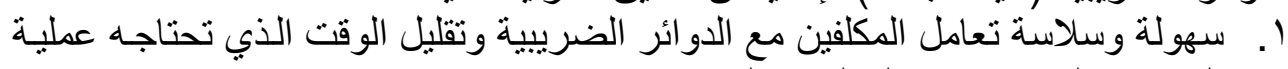

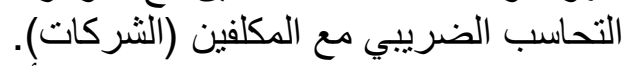

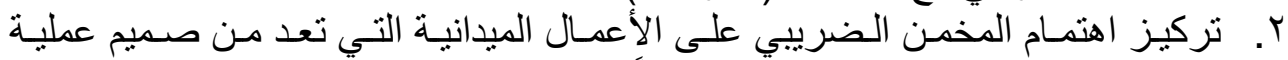

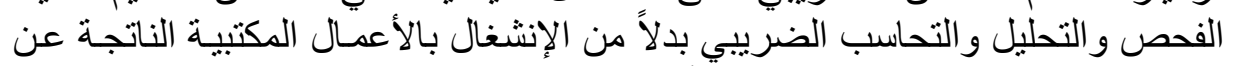

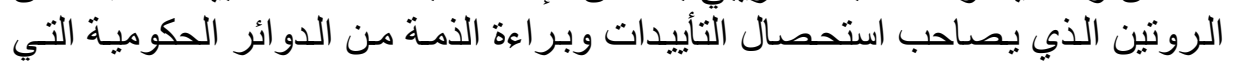

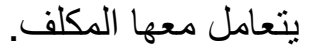


r. السر عة و الدقة في تبـادل المعلومـات بين الأقسام الفرعيـة من جهة وبين الإدارة العليا

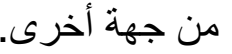

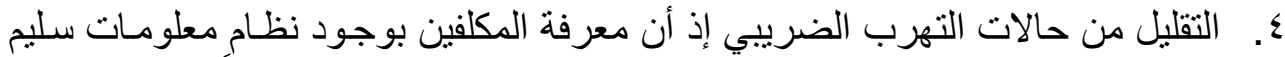

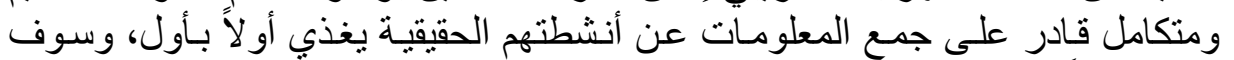

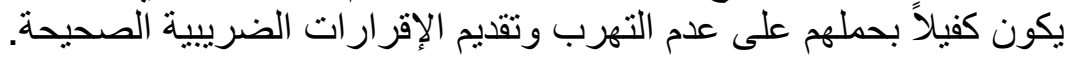

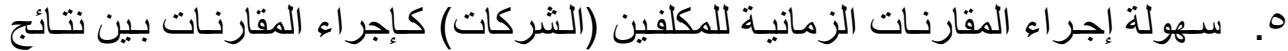
مجمو عة من السنو ات للشركة نفسها أو إجر اء المقارنة التهاء مع نتائج شركات مماتلكة.

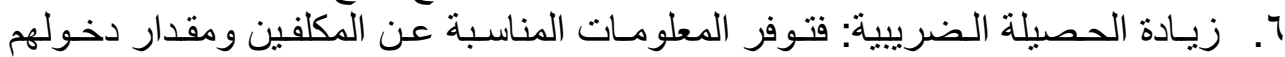

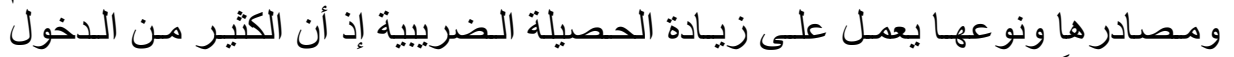

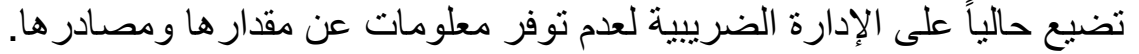

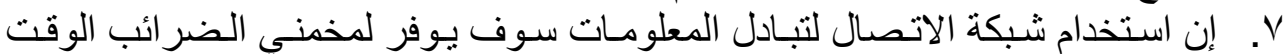

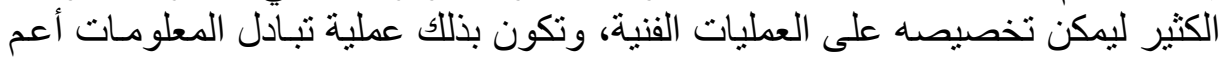
و أثنمل على مستوى المديرية بالكامل، وذللك في تجميع الإير ادات المحصلة ولئل وتحليلها

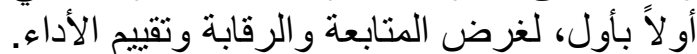

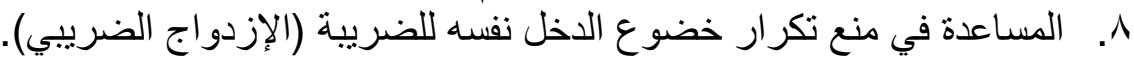

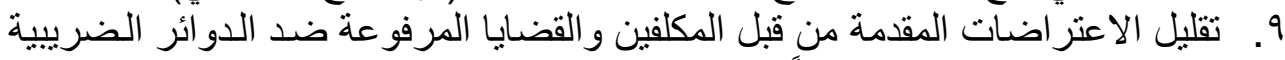

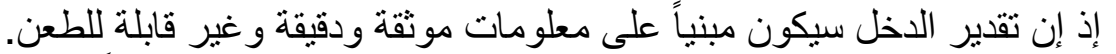

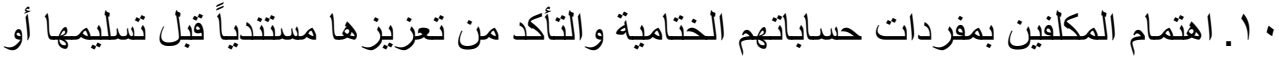

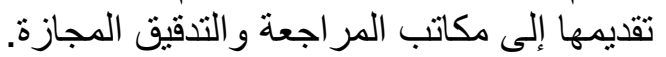

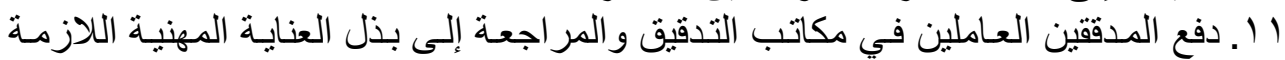

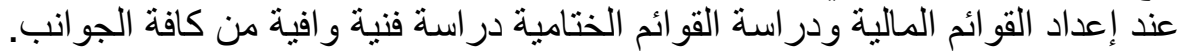

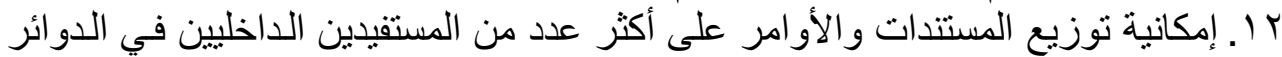

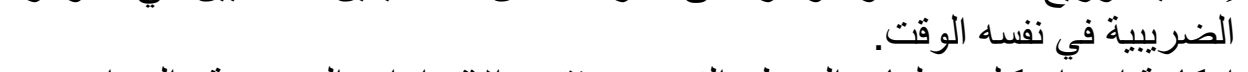

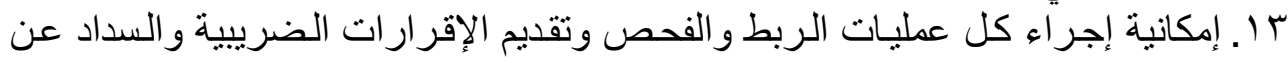
طريق الميكنة الكاملة. ع ا ـ تقليل التعامل الشخصي بينة المكلفين و الدوائر الضريبية الذي عـادة مـا يولد نو عين من التصرف: التصل الأول: وهو الحياد إلى جانب المكلف و الخضوع للأهو اء الثخصية.

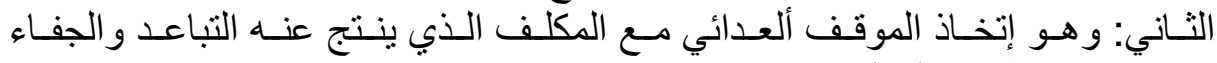
بين طرفي العملية.

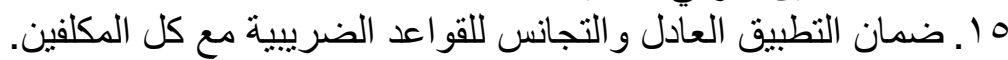

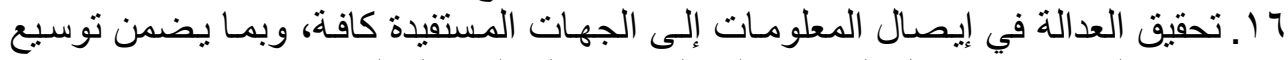

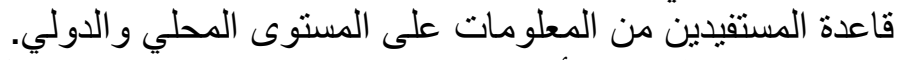

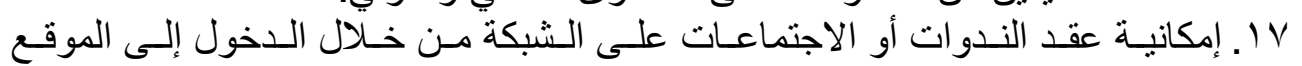

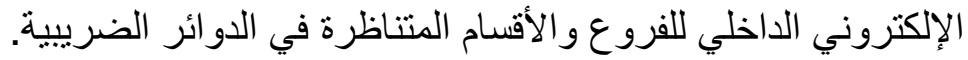

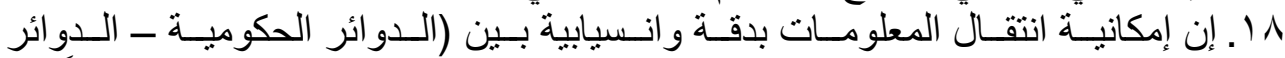

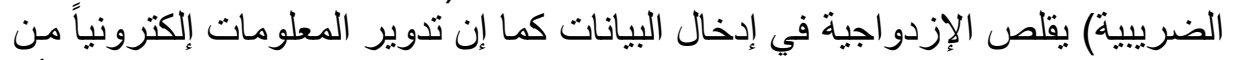

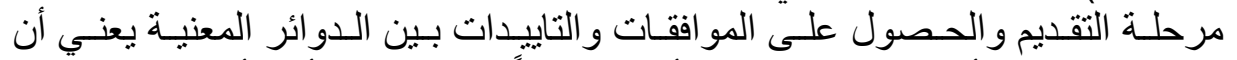

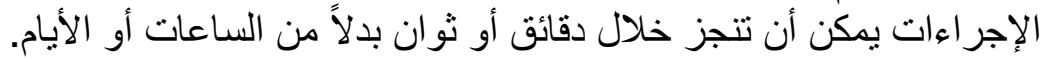




\section{خ خلي]}

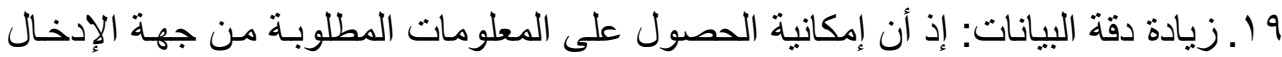

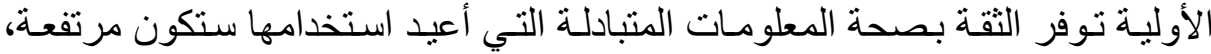
وسيغيب القلق من عدم دقة المعلومات أو الأخطاء الناتجة عن الإدخال الإلة اليدوي.

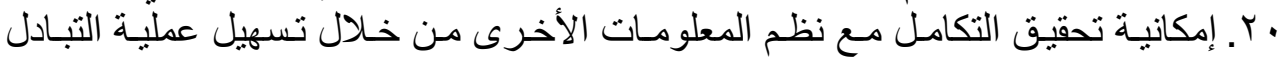
ب الإلكتروني للبيانات فيما بينها.

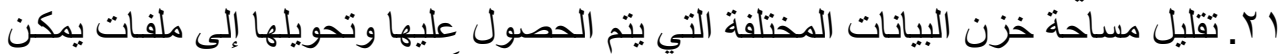
استداؤها هباثرة من قاعدة البيانات المركزيـة، فضلاً عن إمكانيـة تحديث (Update)

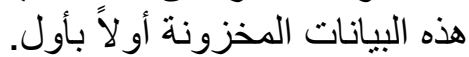

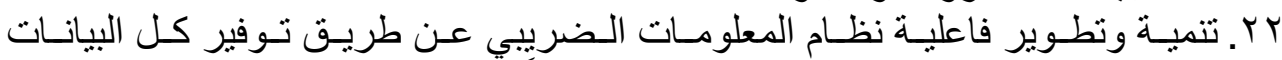

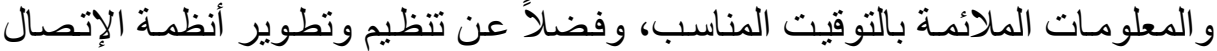

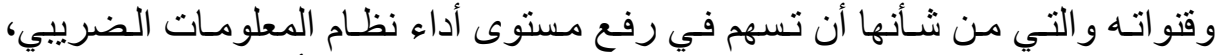

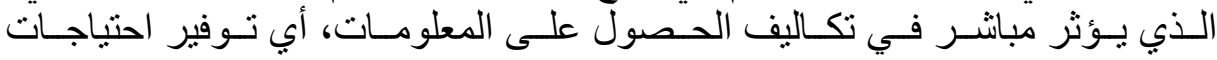
المستفيدين من المعلومات بتكلفة معقولة ولة ومناسبة.

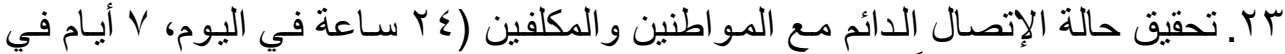

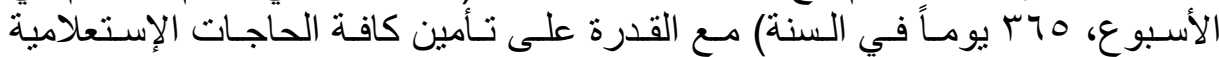
و الخدمية للمو اطنين.

ثانياً - منطبات تطبيق النظام

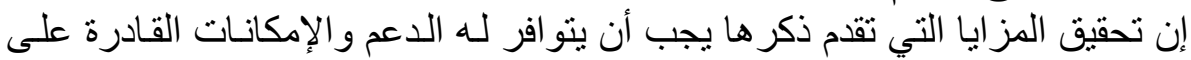

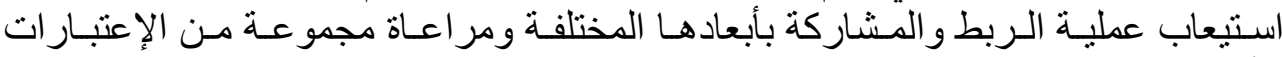

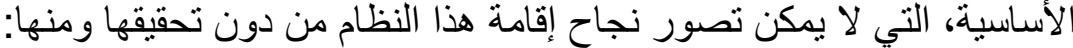

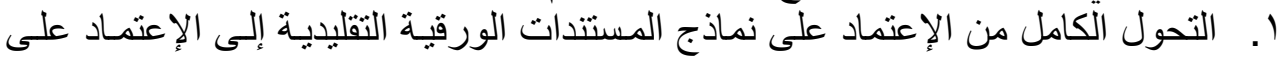

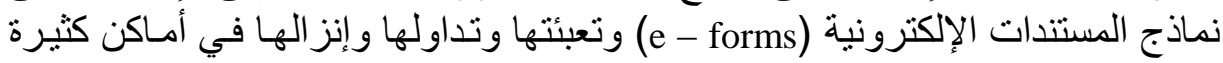
عبر الثبكة الإلكترونية.

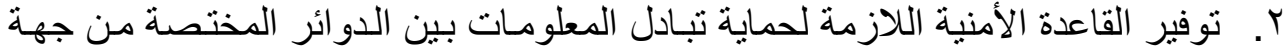

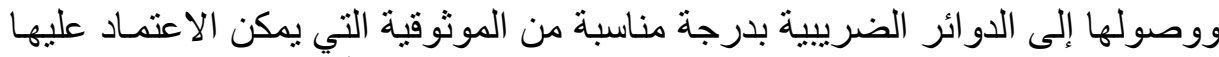

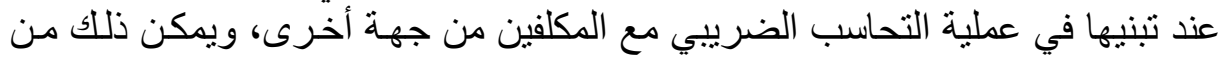

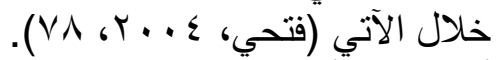
تقوية أنظمة الحماية من خلال فصل قو اعد البيانات بعضها عن بعض ووضعها

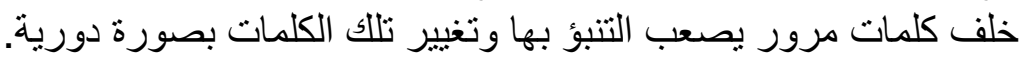

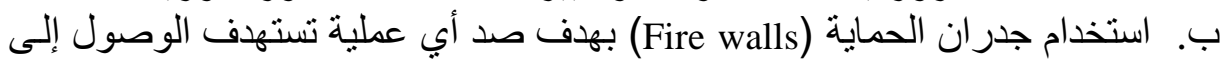
المعلومات بطريقة غير مباشرة. ت. حماية قواعد البيانات باستخدام قو اعد التشفير المتقدمة (أحد أسـاليب الحمايـة الذي الذي

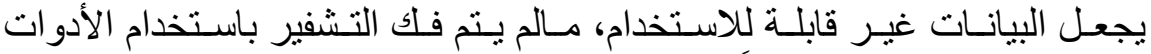

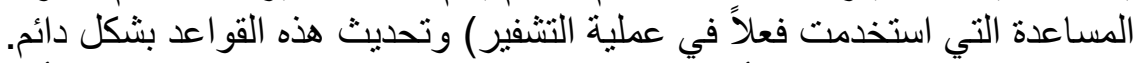
ث. مماية قو اعد البيانات من الأضرار و التلف عن طريق الإحتفاظ بالمعلومـات بأكثر

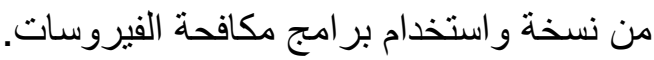

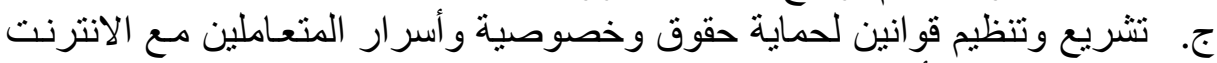

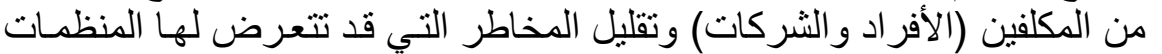




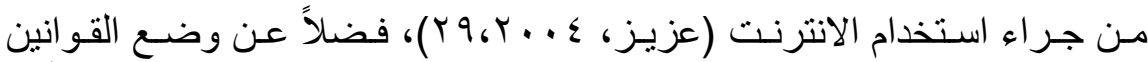

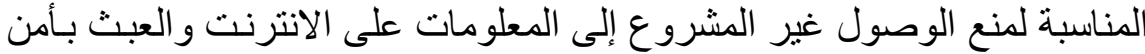

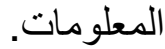

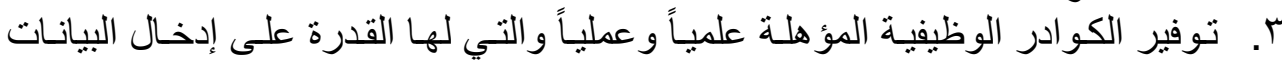

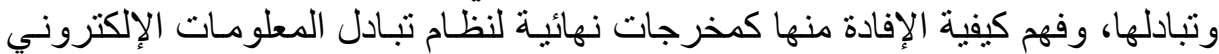

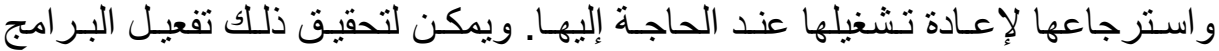

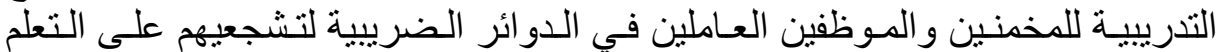

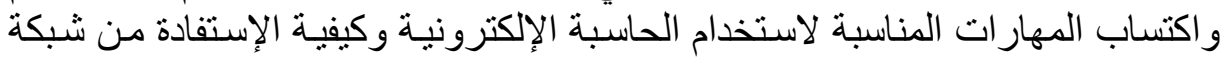

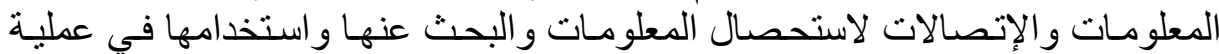
التحليل و التحاسب الضريبي.

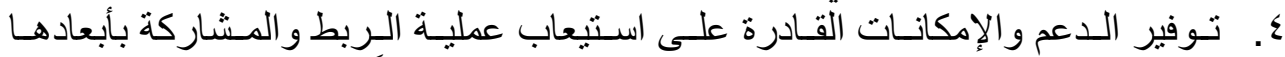

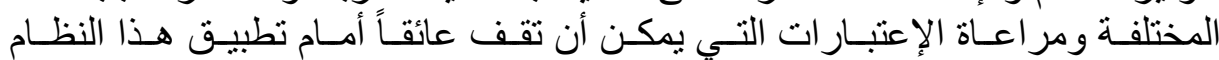

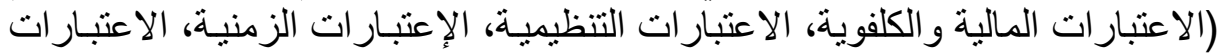

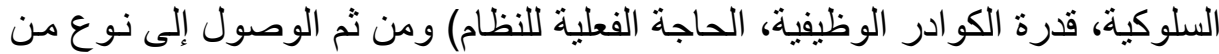

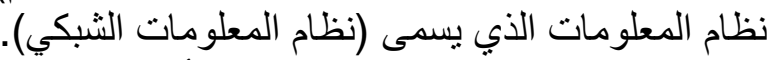

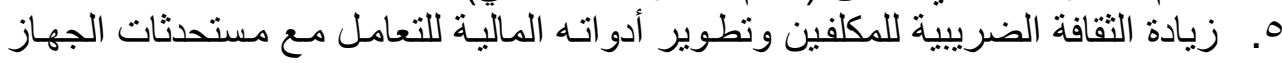

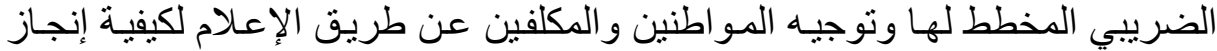
المعاملات الضريبية عبر شبكة الانترنت.

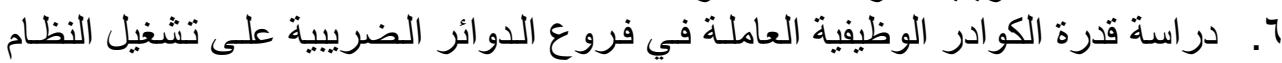

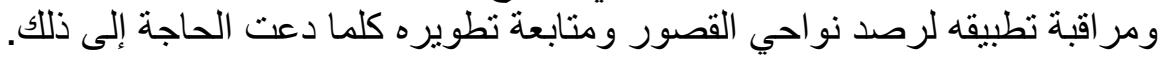

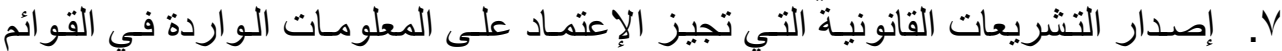

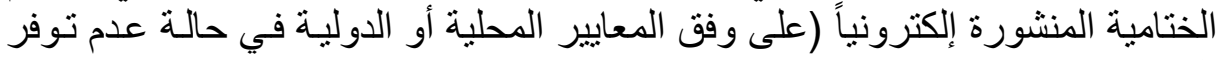

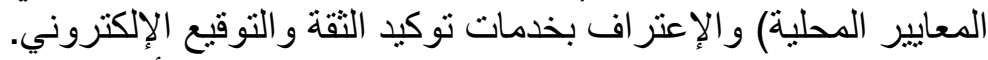

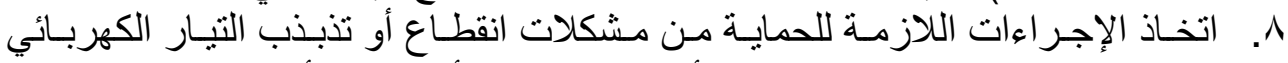

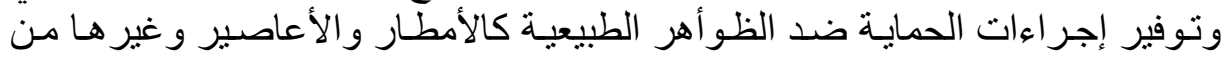
الظو اهر الطبيعية.

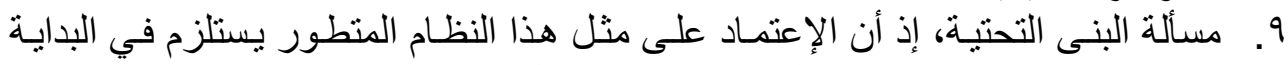

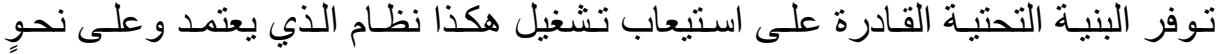

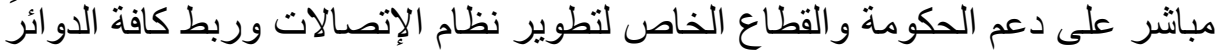

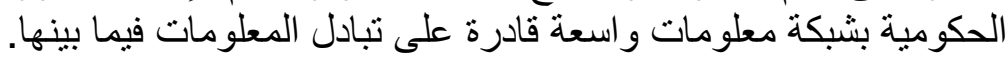

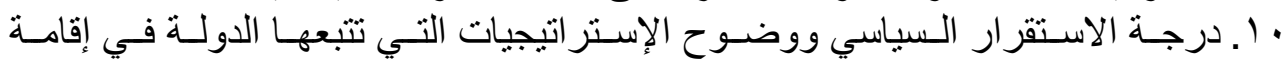
المشاريع الجديدة. 11 ـ الدعم الإعلامي للمشروع وتوضيح المزايا الممكن تحقيقها من استخدامه.

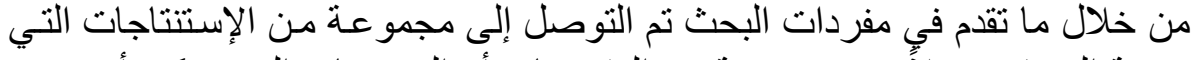

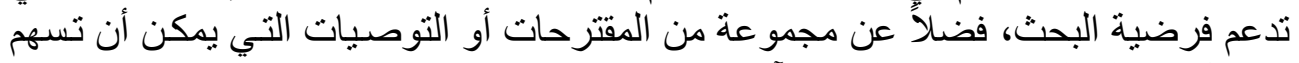

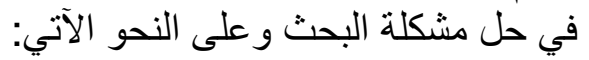




\section{خليا[010}

أولاًا- الإستنتاجات

ا. . إن الدوائر الضريبية (عينة البحث) تفتقر في الوقت الرات الهن إلى مـا يمكن عده نظـام

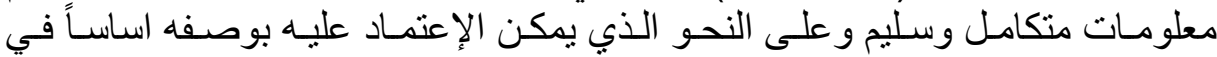
عمليتي حصر المكلفين واستحصال المعلومات (المقتبسات) عن المكلفين بضريبة دخل الثركات. r. تقدم تقانة شبكة المعلومات و الإتصالات مجالاً و اسعاً للاستفادة من تطبيقات هذه التقانة

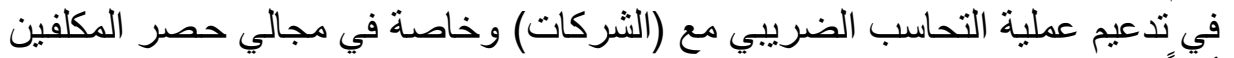

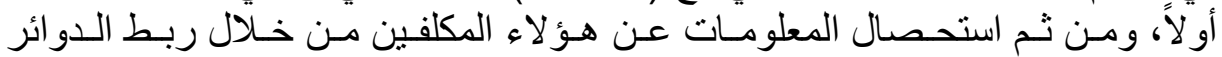

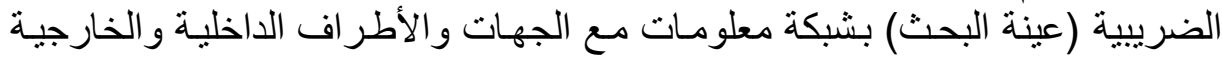

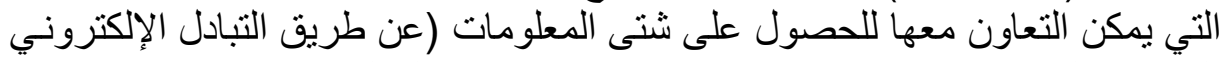

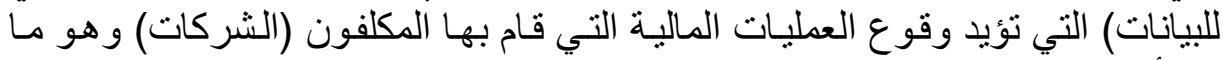

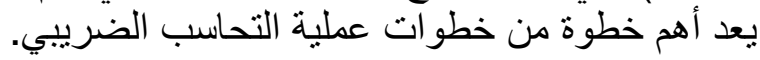

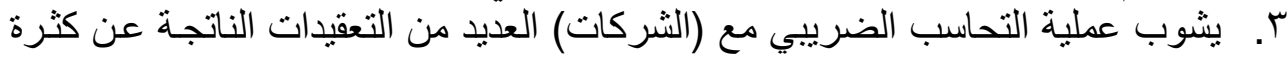

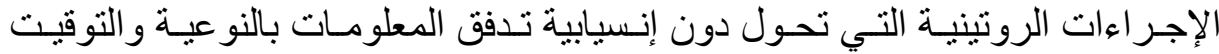

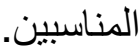

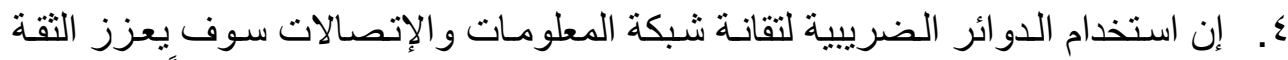

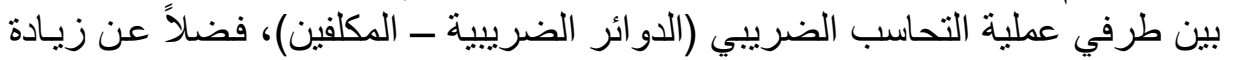

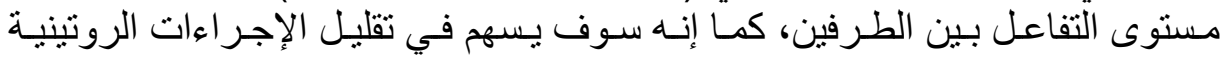

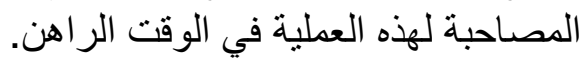

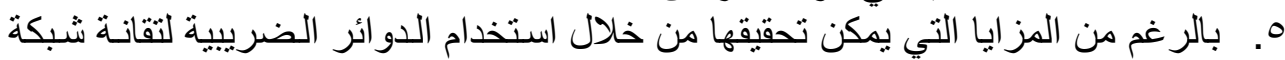

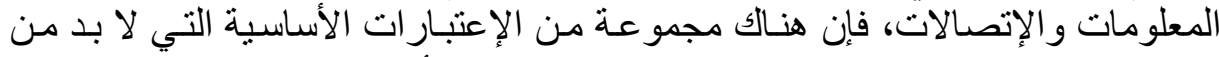

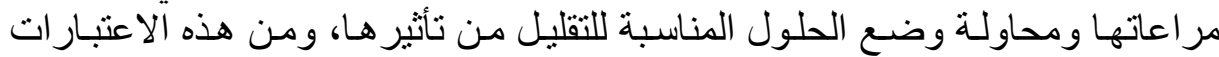

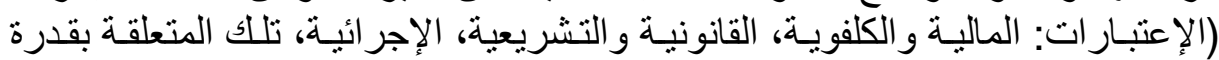

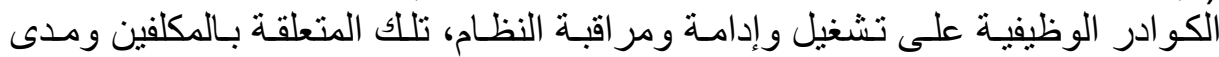
تقبلهم للتعامل مع هذه التقانة، الإعتبار ات المتعلقة بسرية أو أمن المعلومات).

ثناتياً- التوصيات

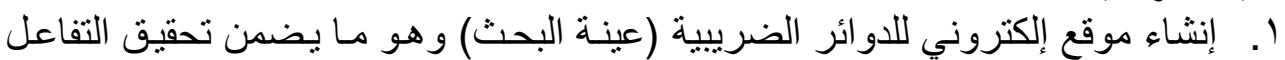

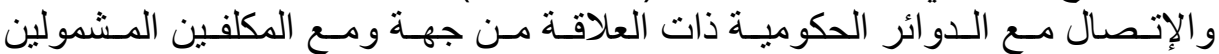

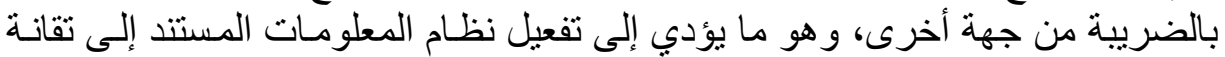
شبكة المعلومات و الإتصالات.

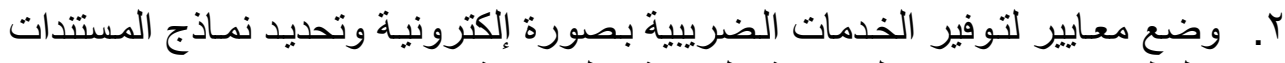
و البطاقات و الإقرارات الضريبية بالصيغة الإلكترونية (e - form).

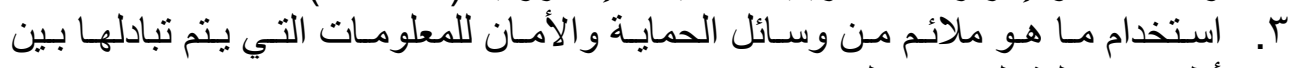

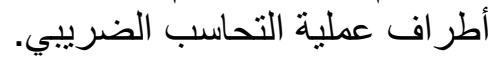
ع. إعادة النظر في تخطيط القوى العاملة في الدوائر الضريبية، وتأهيل الكوادر الوظيفيبة

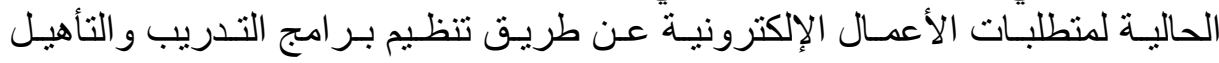




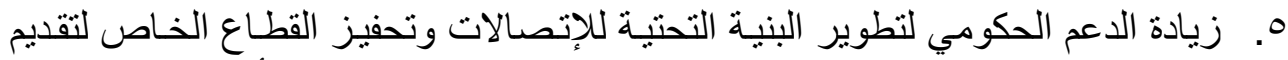

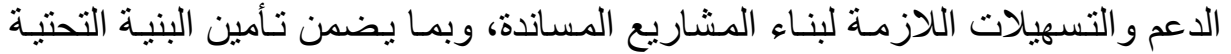

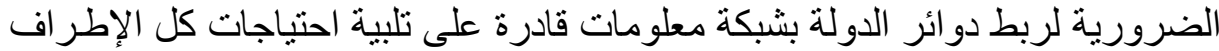
المستفيدة من هذه المعلومات.

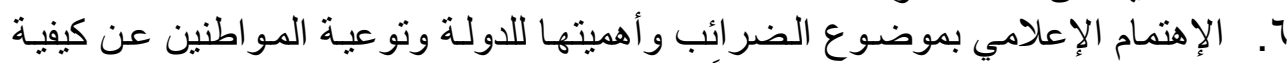

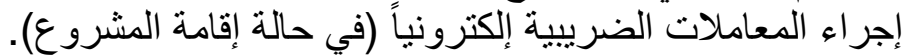
V . . إصدار القوانين و التشريعات الملائمة لبيئة التعاملات الإلكترونية.

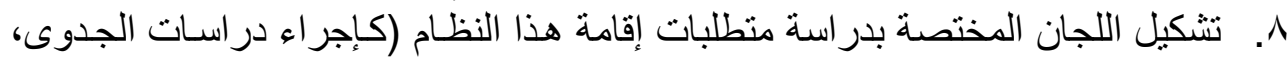

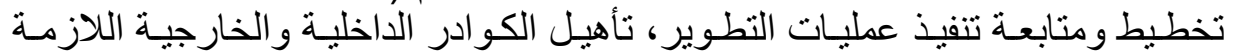

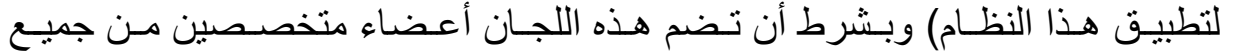

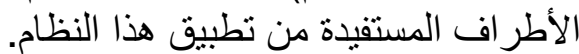

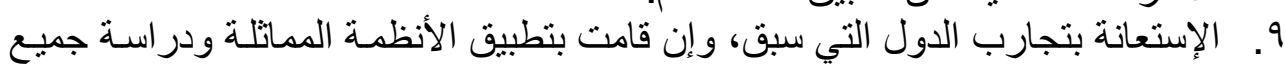
نواحي تطبيق هذه التجارب لتلافي الوقوع في الأخطاء و الإنحر افات ألثناء إقامـة النظـام (مع مر اعاة مدى ملاعمة هذه التجارب للتطبيق على البئئة المحلية).

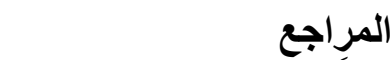

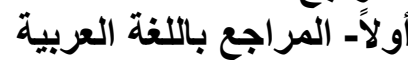

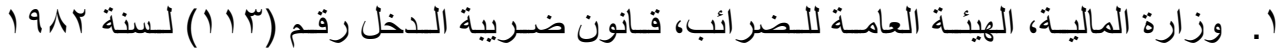

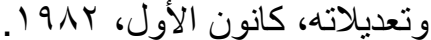

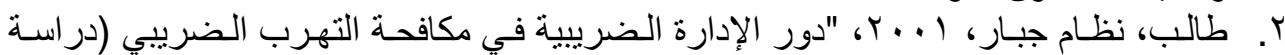

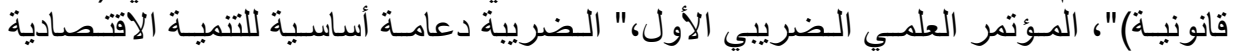

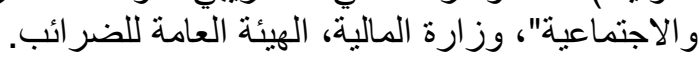

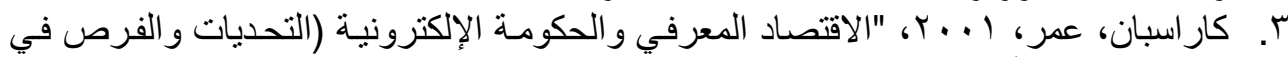
منطقة الثرق الأوسط وشمال إفريقيا)"، ندوة الحكومة الإلكترونية المنعقدة في سفط (عمان)،

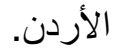

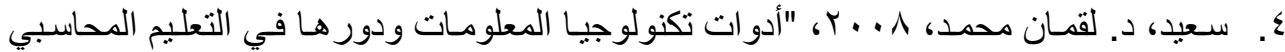

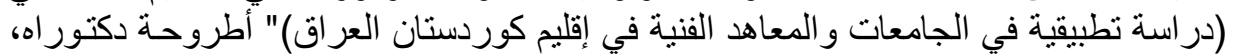
غير منشورة، جامعة بغداد، العراق.

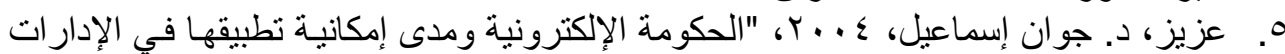

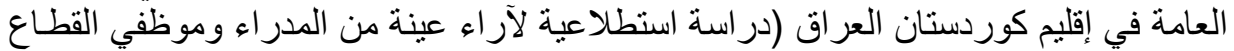

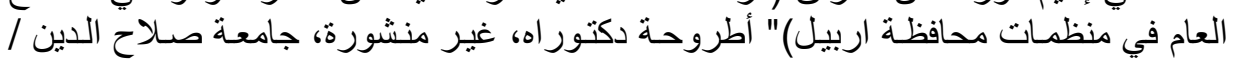

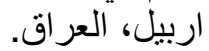

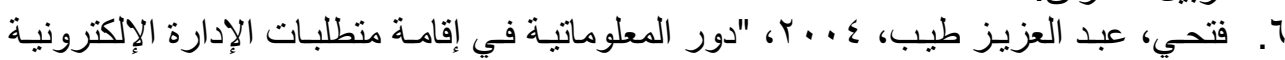

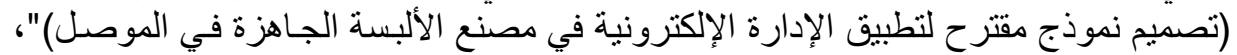

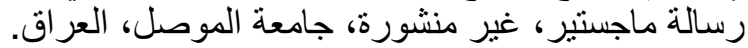

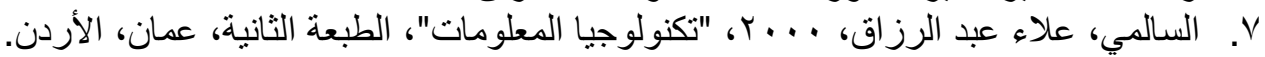

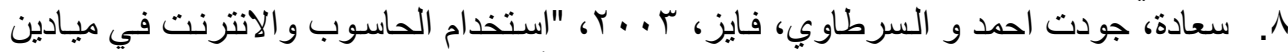

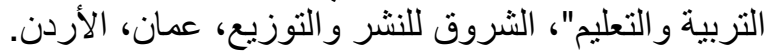

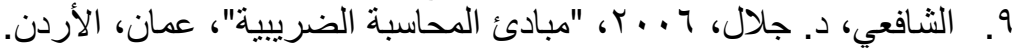

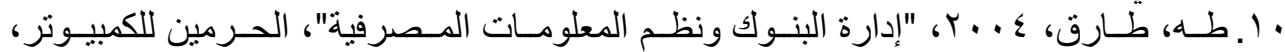

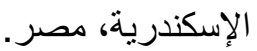




\section{خليا[نr]}

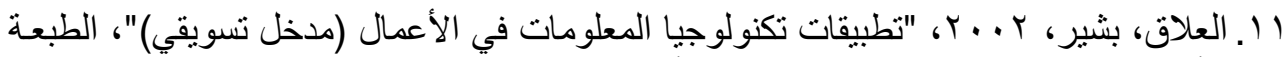

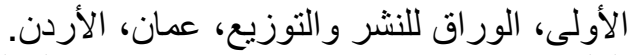

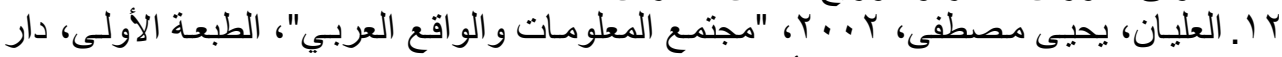

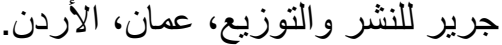

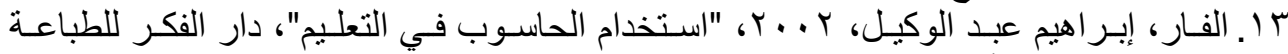

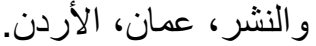

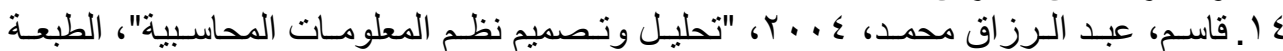
الأولى، دار الثقافة للنشر والتوزيع، عمان، الأردن.

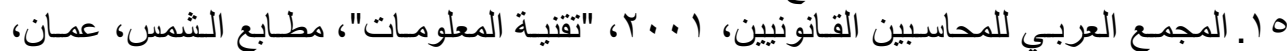

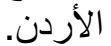

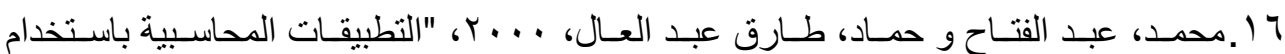
الحاسب"، مطبعة الدار الجامعية، الإسكندرية، مصر.

\section{ثانياً المراجع باللغة الأجنبية}

1. Gallegos, and Fredrick, 2004, "Information technology (Control and audit)", 2nd Ed, Auerbach pub. USA.

2. Turban E. Riner and Potter E. Richard, 2003, "Introduction to information technology", $2^{\text {nd }}$ E., John Wiley and Sons, Inc, USA.

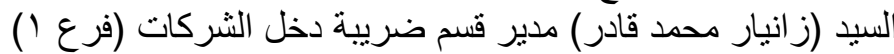

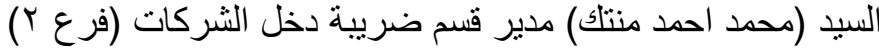

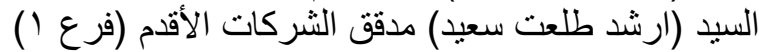

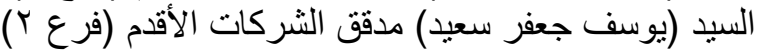

